AnUARIO DE Estudios MediEVALES

44/2, julio-diciembre de 2014, pp. 945-981

ISSN 0066-5061

doi:10.3989/aem.2014.44.2.09

\title{
EL BROCADO DE ESTAÑO EN RELIEVE APLICADO. EVOLUCIÓN HISTÓRICA Y MATERIAL EN LA EUROPA MEDIEVAL CON ATENCIÓN AL ARTE ESPAÑOL (SIGLOS XV-XVI) ${ }^{1}$
}

\author{
APPLIED TIN-RELIEF BROCADE. HISTORICAL AND \\ MATERIAL DEVELOPMENT IN MEDIEVAL EUROPE \\ FOCUSING ON SPANISH ART (15th-16th CENTURIES)
}

\author{
AINHOA RODRÍGUEZ LÓPEZ \\ Universidad del País Vasco (UPV/EHU) \\ FERNANDO BAZETA GOBANTES \\ Universidad del País Vasco (UPV/EHU)
}

Resumen: El término brocado de estaño en relieve aplicado (comúnmente conocido como brocado aplicado) se refiere a una decoración polícroma que imita los brocados de terciopelo y seda hechos con hilos de oro y plata, los cuales dominan el mundo de la moda de Europa en los siglos XV y XVI. Esta técnica reproduce mecánicamente a través de una matriz, lámina de estaño y masa de relleno motivos en relieve de brocados textiles, que, una vez recortados, son aplicados sobre la obra, pudiendo estar en ocasiones dorados y pintados. El hallazgo de más ejemplos de esta decoración en el Norte de España nos ha conducido a analizar las fuentes documentales, especialmente las españolas, con el objetivo de ampliar nuestro conocimiento sobre la técnica en cuestión, su evolución histórica y material y sus diferentes tipologías. Asimismo, dicho estudio nos ha proporcionado un importante glosario de técnicas pictóricas en relieve por adición precursoras del brocado de estaño en relieve aplicado.

\begin{abstract}
The term applied tin-relief brocade (commonly called applied brocade) refers to painted decoration that simulates the velvet and silk brocades made of gold and silver threads commonly used in Europe in the fifteenth and sixteenth centuries. This technique uses a mould, tin leaf, and filling mass to reproduce in a mechanical way the relief motifs of textile brocades. Once cut, they are applied to artwork, and then sometimes gilded or painted. The discovery of many examples of this type of decoration in northern Spain has led us to the study of the documentary sources, especially Spanish ones, with the purpose of improving our understanding of the technique, its historic and material development, and the typology of standardized patterns. Furthermore, this study has provided us with an important glossary of the relief painting additive techniques that culminated in applied tinrelief brocade.
\end{abstract}

1 El presente artículo forma parte del proyecto "Estudio de técnicas pictóricas en relieve en el País Vasco" financiado por el programa de Becas Postdoctorales del Gobierno Vasco y desarrollado en 2011 en el Straus Center for Conservation and Technical Studies-Harvard Art Museum y la Facultad de Letras de la Universidad del País Vasco (UPV/EHU). 
Palabras clave: brocado aplicado; técnicas en relieve; técnicas pictóricas; estaño; masa de relleno; retablos.
Keywords: applied brocade; relief techniques; painting techniques; tin; filling mass; altarpieces.

\section{SUMARIO}

1. Introducción.- 1.1. Proceso de ejecución del brocado de estaño en relieve aplicado.- 2. Estado de la cuestión.- 2.1. Causas y consecuencias del desconocimiento de la técnica.- 2.2. Implicaciones del hallazgo de nuevos motivos.- 2.3. Análisis de las fuentes documentales.- 3. Evolución histórica y material.- 3.1. Origen.- 3.2. Período de uso.- 3.3. Artífices.- 4. Tipologías y temáticas.- 4.1. Motivos yuxtapuestos.- 4.2. Motivos sueltos.- 5. Conclusión.- 6. Glosario de términos sobre técnicas pictóricas en relieve por adición.- 6.1 Metal recortado.- 6.2. Papel recortado.- 6.3. Relieve a mano alzada.- 6.4. Relieve moldeado simple.- 6.5. Papel moldeado.- 6.6. Relieve de estaño.- 6.7. Brocado de estaño en relieve aplicado.- 7. Bibliografía citada.

\section{INTRODUCCIÓN}

El brocado de estaño en relieve aplicado se ha empleado en una gran variedad de obras de arte, entre las cuales se incluyen: retablos de madera, esculturas de madera, esculturas de piedra (por ejemplo, caliza), relieves de madera, pinturas sobre tabla, pinturas murales, pinturas sobre lienzo y artesonados de madera.

El objetivo de este artículo es presentar una revisión detallada del brocado de estaño en relieve aplicado desde una perspectiva histórica, material y estilística, con atención a los casos hallados en España. En el artículo, mediante el análisis de la documentación (publicada y sin publicar) sobre brocados de estaño en relieve aplicados, localizados en retablos de madera, se pretende poner de manifiesto la importancia de este tipo de obra, pues se trata de la que más ejemplos de esta decoración presenta, tanto dentro como fuera de las fronteras españolas. A través del estudio de las fuentes documentales se profundiza en la historia, incluyendo el origen y decadencia, y las tipologías y motivos. Paralelamente, ha sido fundamental el examen de las técnicas en relieve por adición que participaron en el nacimiento del brocado de estaño en relieve aplicado y que ha concluido en un glosario original de términos y descripciones incluido en un apartado final. La clasificación de las técnicas que se presenta se fundamenta en importantes diferencias técnicas (de ejecución), materiales y/o estilísticas que permiten su caracterización ${ }^{2}$.

\footnotetext{
2 De ahí que el empleo del término "técnica" en este artículo se refiera a aquel procedimiento decorativo pictórico con unas características específicas de ejecución (o técnica), de materiales y de estilo.
} 
El interés de este artículo es contribuir al mejor conocimiento y entendimiento de la técnica del brocado de estaño en relieve aplicado, en particular, y de las técnicas en relieve por adición, en general, para, por un lado, mejorar nuestra capacidad de detectar nuevos casos en los revestimientos pictóricos de las obras de arte del patrimonio español y, por otro lado, poner a disposición de los especialistas en distintas disciplinas una terminología precisa y unificada que facilite la transmisión de conocimientos en la materia.

\subsection{Proceso de ejecución del brocado de estaño en relieve aplicado}

Aunque este artículo se centra en aspectos históricos y estilísticos de la técnica, es necesario exponer el procedimiento de elaboración del brocado de estaño en relieve aplicado que se puede resumir en las siguientes ocho fases:

1. Grabado de lo que será la matriz.

2. Colocación de la lámina de estaño sobre la matriz.

3. Impresión de la matriz en la lámina de estaño.

4. Rellenado del grabado de la lámina de estaño con un material semilíquido.

5. Separación de la lámina de estaño de la matriz.

6. Recorte de los motivos de brocado de la lámina de estaño.

7. Aplicación de los motivos sobre la superficie de la obra.

8. Dorado y pintado de los brocados de estaño en relieve aplicados (opcional).

La primera fase del proceso es la creación de la matriz donde se graba el motivo de brocado ${ }^{3}$. Teniendo presente que el motivo grabado reproduce los hilos del brocado textil y que hasta la fecha no se han encontrado matrices originales, numerosos estudiosos han partido del análisis visual de brocados de estaño en relieve aplicados y de las fuentes documentales antiguas $^{4}$ para realizar reproducciones de matrices que nos aproximen a su naturaleza. Estas reconstrucciones apuntan que los materiales más probables de las matrices eran maderas duras (como madera de cerezo y de peral), metales (como plomo, latón y cobre), pizarra, una mezcla de creta y cola

3 M.S. Frinta, The use of wax for appliqué relief brocade on wooden statuary, p. 143.

4 Las únicas fuentes escritas antiguas conocidas que más se ajustan al proceso de elaboración del brocado de estaño en relieve aplicado son aquellas que específicamente se refieren a la producción del relieve de estaño, como explicamos más adelante. Véase C. Cennini, El Libro del Arte, pp. 165, 209-211; M.J. González, Brocado aplicado, pp. 70-72, 76-77. 
y piedra ${ }^{5}$. El empleo de una matriz rígida tiene la ventaja de reproducir el motivo tantas veces como se desee ${ }^{6}$.

En la segunda fase una o varias láminas de estaño se colocan sobre la matriz.

A continuación, en el tercer paso, el estaño se cubre con un material amortiguador como puede ser estopa sobre el que se ejerce presión golpeando con un mazo de madera. Así se logra imprimir el motivo de la matriz en el estaño?

En la cuarta fase se rellenan los huecos del estaño con un material semilíquido. Las fuentes documentales citan una amplia variedad de materiales que constituyen las diferentes mezclas de rellenos que se dividen en dos grupos: rellenos lipídicos o grasos y rellenos proteínicos o magros. El material de relleno debe calentarse y posteriormente aplicarse sobre el estaño con una espátula de modo que cubra toda la superficie del estaño rellenando los huecos del grabado ${ }^{8}$.

La quinta fase comienza cuando el relleno está casi seco. Entonces la lámina de estaño se separa de la matriz ${ }^{9}$.

Una vez separada, en la siguiente fase, se recorta de acuerdo a cómo va a ser decorada la superficie de la obra. Existen dos tipologías de decoración y de brocados de estaño en relieve aplicados y, en consecuencia, dos modos diferentes de recortar, adherir y decorar los motivos de brocado. La primera tipología de decoración es continua donde los bordes de los motivos son rectos resultando en brocados cuadrados o rectangulares con el mismo motivo. Estas formas permiten la unión continuada de brocados iguales creando una decoración uniforme. Esta tipología de decoración y brocado de estaño en relieve aplicado es conocida como yuxtapuesta. A la segunda tipología se la conoce por el nombre de aislado o suelto, ya que los motivos de brocado se aplican de forma aleatoria sin cubrir toda la superficie. Los motivos suelen ser diferentes y se recortan siguiendo sus contornos ${ }^{10}$.

En la séptima fase se aplican los brocados a la superficie de la obra. Tanto los brocados yuxtapuestos como los sueltos se han detectado adheridos con adhesivo compuesto de diferentes combinaciones de cera, resina, aceite, cola animal, creta y pigmentos de color. A pesar de que lo más común sea adherir los motivos de brocado con un estrato extra de adhesivo ${ }^{11}$, es bastante

5 A. Rodríguez, Decoración polícroma en relieve. El brocado aplicado, p. 66; I. Geelen, D. Steyaert, Imitation and Illusion, p. 69.

6 A. Tavares da Silva, The decorated background, p. 47.

7 C.L. Bowman, Pasteprints, p. 8; M.J. González, Brocado aplicado, pp. 70-72.

8 M. Serck-Dewaide, The history and conservation, p. 68; C.L. Bowman, Pasteprints, p. 8.

9 K.-W. Bachmann, E. Oellermann, J. Taubert, The conservation and technique, p. 356.

10 M.J. González, Brocado aplicado, pp. 73, 74.

11 J. Nadolny, Documentary Sources, p. 47. 
frecuente hallar brocados sueltos aplicados directamente sobre corladuras que en estado mordiente actúan como adhesivos y, aunque en raras ocasiones, es también posible encontrar brocados yuxtapuestos sin estrato de adhesivo ${ }^{12}$.

La octava y última fase del proceso consiste en la decoración de color de la lámina de estaño. En general, la lámina de estaño se dora con lámina de oro empleando mixtión (constituido por distintas mezclas de resina, aceite -normalmente de linaza-, cola animal, huevo, creta y pigmentos de color) y después, las zonas planas son pintadas con pinturas opacas o corladuras (de color rojo, azul, verde, negro y blanco) para resaltar el motivo del brocado ${ }^{13}$. La práctica común es dorar y pintar los motivos de brocado yuxtapuesto una vez que han sido adheridos sobre la zona de la obra a decorar, mientras que los brocados sueltos son dorados antes de su aplicación sobre la obra y una vez adheridos son pintados ${ }^{14}$.

En resumen, la estructura característica del brocado de estaño en relieve aplicado -de abajo a arriba- es la siguiente: preparación, imprimación, adhesivo, masa de relleno, lámina de estaño, mixtión, lámina de oro, y pintura opaca y corladura. El estrato de adhesivo, situado entre la imprimación y la masa de relleno, en ocasiones no se aprecia debido a su escaso espesor, como sucede en la imagen 1.

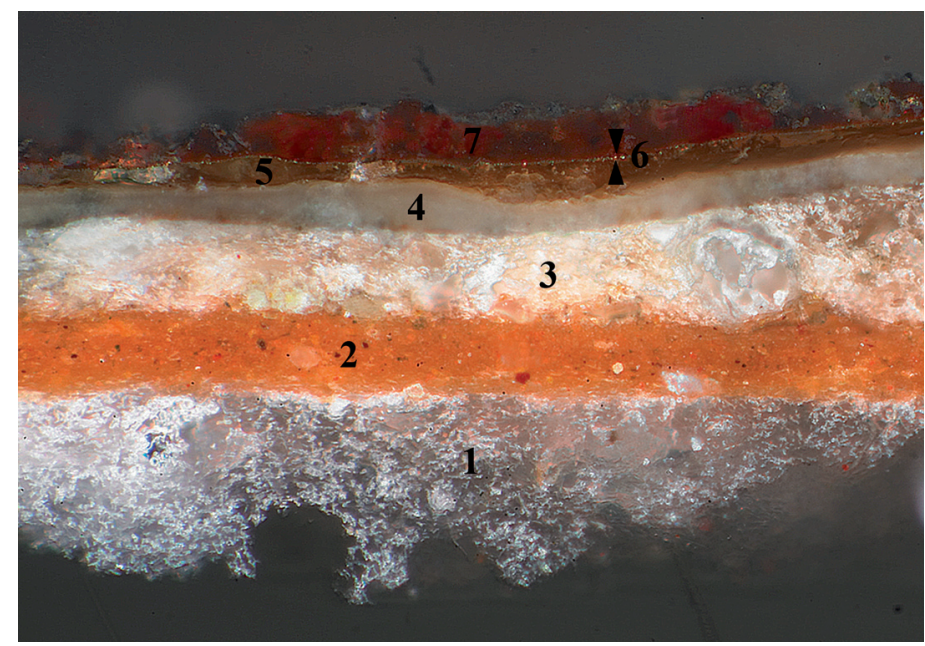

Fig. 1. Estratigrafía de un brocado de estaño en relieve aplicado yuxtapuesto. Retablo de la Santísima Trinidad. 1531-1533. Monasterio de Bidaurreta, Oñate (Guipúzcoa).

12 J.A. Darrah, White and golden tin foil, pp. 66, 69, 70, 76, 77.

13 T. Gómez, Policromía del gótico final, p. 575.

14 M. Serck-Dewaide, The history and conservation, p. 70. 


\section{ESTADO DE LA CUESTIÓN}

\subsection{Causas y consecuencias del desconocimiento de la técnica}

El brocado de estaño en relieve aplicado está considerado una de las técnicas pictóricas decorativas más detallistas y laboriosas a nivel técnico y material que se utiliza en el revestimiento polícromo de imaginería y pintura en Europa. Sin embargo, también está considerada como una de las técnicas de pintura más desconocidas. Este importante desconocimiento del brocado de estaño en relieve aplicado tiene diversas causas ${ }^{15}$.

En primer lugar, la escasez de estudios de la técnica, en particular en España ${ }^{16}$. Fundamentalmente se detecta un notable vacío en lo que respecta a investigaciones con una metodología científica específica. De ahí que todavía existan en el presente numerosas incógnitas referentes a aspectos históricoartísticos y técnicos ${ }^{17}$.

Esta carencia de documentación, en un segundo plano, dificulta la divulgación y mejor conocimiento del brocado de estaño en relieve aplicado y evita la consecución de la formación actualizada de especialistas, tal como apuntan Bruquetas, Carrassón y Gómez del Instituto del Patrimonio Cultural de España (antes denominado Instituto del Patrimonio Histórico Español) ${ }^{18}$.

Una tercera causa del aún escaso conocimiento del brocado de estaño en relieve aplicado es el mal estado de conservación en el que por lo general los ejemplares de este tipo de decoración llegan hasta nuestros días. Este avanzado estado de deterioro se puede todavía detectar en múltiples casos localizados en retablos del País Vasco, como, por ejemplo, el tríptico de la Asunción-Coronación de la Virgen (1505-1510), sito en la iglesia de la Asunción de Santa María, Errenteria, Guipúzcoa. Los motivos, constituidos por al menos ocho capas de diferente naturaleza, tienen difícil conservación debido a la propia fragilidad de la técnica cuya estabilidad depende de la evolución de los múltiples materiales que la componen.

Como última y cuarta causa, hay que señalar el ocultamiento -parcial o total- por medio de repintes o repolicromías de brocados de estaño en relieve aplicados, debido, precisamente, a que es una tipología de decoración pictórica muy frágil que suele presentar importantes lagunas que son ocultadas

15 M.J. González, Brocado aplicado, pp. 67, 68, 74.

16 I. Berasain, M.T. Barriola, Aproximación a la policromía del Retablo de San Antón, p. 383.

17 R. García, E. Ruiz De Arcaute, El "brocado aplicado", una técnica de policromía centroeuropea en Álava, p. 411.

18 R. Bruquetas, A. Carrassón, T. Gómez, Los retablos. Conocer y conservar, p. 46. 
con repintes o repolicromías. En ciertos casos, estos recubrimientos pictóricos tienen lugar como consecuencia de cambios de gustos o estilos artísticos. Un claro exponente de repolicromías sobre brocados de estaño en relieve aplicados es el retablo de San Juan Bautista (circa 1530-1555) emplazado en la iglesia de San Miguel Arcángel, Oñate, Guipúzcoa.

Toda esta serie de condiciones ha derivado en la incomprensión y falta de identificación o reconocimiento de la técnica en obras de distinta tipología. En ocasiones, cuando ha sido identificada ha sido sometida a procesos devastadores con resultados poco afortunados motivados por tratamientos y productos de conservación-restauración habituales sobre otras técnicas de pintura, pero que, aplicados sobre la técnica que nos ocupa, tienen consecuencias nefastas para su conservación ${ }^{19}$.

\subsection{Implicaciones del hallazgo de nuevos motivos}

En las cinco últimas décadas se han descubierto en Europa nuevos casos de brocado de estaño en relieve aplicado en distintos tipos de obra (predominando los retablos). Estos hallazgos han conllevado dos realidades.

La primera es que el uso del brocado de estaño en relieve aplicado no es tan excepcional o inusual como se creía en un principio. Sin embargo, sigue siendo un método muy sofisticado en la ornamentación de imaginería, que denota la importancia de la obra puesto que, salvo excepciones, siempre se detecta en trabajos de gran riqueza artística ${ }^{20}$.

La segunda realidad es el interés por desarrollar estudios sobre la técnica en cuestión. Así, en las últimas dos décadas, se detecta un aumento de investigaciones y publicaciones en España y otros países de Europa que sin duda alguna están contribuyendo al reconocimiento y adecuada conservación del brocado de estaño en relieve aplicado.

\subsection{Análisis de las fuentes documentales}

Las primeras publicaciones dedicadas íntegramente a la técnica del brocado de estaño en relieve aplicado datan de 1963 y son debidas a Mojmír S. Frinta y Thomas Brachert. Ambos autores llevan a cabo una primera aproximación, no del todo completa, al proceso de elaboración. Aun-

19 M. Serck-Dewaide, Relief decoration on sculptures and paintings, p. 37; M.J. González, Brocado aplicado, p. 74.

20 R. García, E. Ruiz de Arcaute, Aproximación al brocado aplicado en España, p. 748. 
que muy brevemente, María Elena Gómez Moreno, en su publicación de $1943^{21}$, se refiere al brocado de estaño en relieve aplicado con el término técnica flamenca del grabado o de la cera. Sin embargo, es sobre todo a partir de las publicaciones de Frinta y Brachert en 1963 cuando diferentes autores comenzaron a describir y analizar ejemplos de la técnica en retablos y esculturas ubicados en Alemania y los Países Bajos; lugares donde se localizan algunos de los casos más antiguos de brocado de estaño en relieve aplicado y donde, por consiguiente, más retablos de madera aparecen todavía con decoraciones de esta técnica pictórica ${ }^{22}$. Concretamente, el primer estudio que analiza en profundidad el brocado de estaño en relieve aplicado es el publicado en dos artículos de 1970 con motivo del análisis históricoartístico, científico y conservador-restaurador del retablo de Friedrich Herlin en la iglesia de St. James en Rothenburg, Alemania ${ }^{23}$.

En España, en 1988 se comenzó a estudiar con mayor frecuencia la técnica del brocado de estaño en relieve aplicado desde un punto de vista histórico y científico. En este mismo año coincidieron dos significativos descubrimientos de la técnica en el País Vasco que vieron la luz en dos publicaciones diferentes de 1991. Una versa sobre los motivos de brocado de estaño en relieve aplicado hallados en el retablo mayor de Santa María de Galdácano en Vizcaya ${ }^{24}$ y la otra sobre la conservación y restauración del retablo Plateresco o de la Santísima Trinidad en el monasterio de Bidaurreta de Oñate en Guipúzcoa ${ }^{25}$. A partir de 1990 fueron principalmente dos las instituciones españolas que se dedicaron al estudio y recopilación de nuevos casos: el Instituto del Patrimonio Cultural de España, en Madrid, y el Servicio de Restauración de la Diputación Foral de Álava, en Vitoria-Gasteiz. En las dos últimas décadas se ha ampliado el número de estudios que han ayudado al conocimiento y difusión del brocado de estaño en relieve aplicado en España por medio de ponencias en congresos, publicaciones especializadas, cursos teórico-prácticos y registros de obras con brocado de estaño en relieve aplicado $^{26}$.

La técnica en cuestión empezó a estudiarse fuera de España un cuarto de siglo antes. Esto explica que la bibliografía actual sobre el tema sea

21 M.E. Gómez, La policromía en la escultura española, pp. 15-17.

22 J.A. Darrah, White and golden tin foil, p. 50.

${ }^{23}$ K.-W. Bachmann, E. Oellermann, J. Taubert, The conservation and technique; M. Broekman-Bokstijn et al., The Scientific examination.

24 M.M. Estrade, El Brocado aplicado.

25 M.A. Arrazola et al., Retablo renacentista de Bidaurreta: restauración, pp. 64-71, 96, 97.

26 Véase el apartado final de "bibliografía citada" para obtener una relación más precisa del material publicado en España sobre el brocado de estaño en relieve aplicado. 
más extensa fuera del territorio español, partiendo de las fuentes tradicionales escritas (tratados de $\operatorname{arte}^{27}$, ordenanzas de pintores y contratos de obra ${ }^{28}$ ) y continuando con la bibliografía especializada de las últimas décadas. Unas obras y otras se encuentran en su mayoría escritas en alemán, francés e inglés. Hay que señalar además que la bibliografía moderna especializada presenta fundamentalmente dos modalidades. Por un lado, aquella que hace un breve repaso histórico y técnico; por otro lado, la que se centra en estudios (analíticos, fundamentalmente) realizados sobre casos hallados en obras durante su proceso de conservación y restauración. Únicamente existe una investigación más detallada en una tesis doctoral que aborda el estudio de las técnicas decorativas en relieve en el Norte de Europa ${ }^{29}$.

Respecto a las publicaciones españolas, predomina la cantidad de documentación inédita en informes que se encuentran en los Servicios de Restauración de las Diputaciones Forales del País Vasco, los Institutos de Patrimonio Histórico y Cultural y las empresas de conservación y restauración. Los contenidos se refieren a los trabajos de conservación y restauración llevados a cabo en retablos y obras aisladas, dedicando un breve apartado a los ejemplos de brocado de estaño en relieve aplicado descubiertos.

Destaca la reciente presentación de una tesis doctoral exclusivamente centrada en el brocado de estaño en relieve aplicado y su uso en la provincia vasca de Guipúzcoa ${ }^{30}$. Los resultados se han publicado en diversas revistas científicas y actas de congresos nacionales e internacionales. En estas publicaciones se han presentado las clasificaciones sistemáticas y localización de las tipologías y temáticas de los motivos detectados en los retablos guipuzcoanos y la caracterización de las aplicaciones técnicas y los materiales empleados en los diferentes estratos, identificados por medio de la aplicación de un protocolo específico original apoyado en técnicas analíticas de laboratorio ${ }^{31}$. En la actualidad se ha ampliado el ámbito geográfico de estudio a toda la provincia del País Vasco, habiéndose abordado en una primera fase el estudio estilístico y material de siete retablos que comparten motivos de brocado también descubiertos fuera de la provincia vasca. La repetición de diseños en distintas obras y localizaciones está permitiendo conocer el uso de esta decoración por los talleres de la zona, las relaciones

\footnotetext{
27 C. Cennini, El Libro del Arte; A. Bartl et al., Der "Liber illuministarum" aus Kloster Tegernsee.

28 J. Nadolny, The techniques and use of gilded relief decoration, vol. I, pp. 333, 334.

29 Ibidem.

30 A. Rodríguez, Análisis y clasificación de los brocados.

31 A. Rodríguez et al., Characterization of calcium sulfate grounds; A. Rodríguez, F. Bazeta, Classification of the Typologies, Techniques and Materials; idem, El brocado aplicado en la retablería renacentista de Guipúzcoa.
} 
entre talleres y la dispersión geográfica y cronológica de motivos, tipologías y materiales ${ }^{32}$.

Siguiendo las indicaciones de las fuentes antiguas y actuales se han llevado a cabo fuera y dentro de España diversas reproducciones de la técni$\mathrm{ca}^{33}$ que han permitido acercarse de forma más real al proceso que hace seis siglos los artesanos empleaban.

El análisis de la documentación existente sobre el tema pone de manifiesto la escasa presencia de trabajos globales y profundos sobre el brocado de estaño en relieve aplicado desde una perspectiva histórica, estilística, técnica y material. Únicamente podemos contar con las dos tesis mencionadas; una a nivel nacional y otra a nivel internacional.

Esta falta de investigaciones especializadas la apuntaba Myriam Serck-Dewaide en $1989^{34}$ y $1990^{35}$ y María José López González en $2000^{36}$. Ambas coincidían en la necesidad de estudios sobre el brocado de estaño en relieve aplicado empleando una metodología sistemática y científica que permitiera, mediante la difusión de la información obtenida, lograr un pleno conocimiento de la técnica y unos adecuados tratamientos de conservación y restauración.

\section{EVOLUCIÓN HISTÓRICA Y MATERIAL}

\subsection{Origen}

Desde el siglo VIII los pintores europeos han adornado sus obras con diferentes adornos en relieve. En un principio, éstas consistían en representaciones de objetos iconográficamente importantes, como halos, realizadas con hojas de metal aplicadas a la obra con clavos ${ }^{37}$. A partir del siglo XII y hasta el siglo XVI, la reproducción verosímil de los textiles de la época impulsó la creación de un amplio repertorio de técnicas en relieve elaborado por pintores con técnicas y materiales pictóricos.

32 A. Rodríguez, F. Bazeta, M.T. Escohotado, El "brocado de estaño en relieve aplicado"; A. Rodríguez et al., Materials and Execution Process of the Relief Painting Technique.

33 A. Rodríguez, Decoración polícroma en relieve. El brocado aplicado, pp. 66-71; O. Cantos, Restauración del retablo mayor, pp. 503-507; B. Hecht, Betrachtungen über pressbrokate sowie Rekonstruktionsversuche unter besonderer Berücksichtigung des sog. Tegernseer Manuskripts, pp. 36-48.

34 M. Serck-Dewaide, Décors en relief, p. 91.

35 Idem, Relief decoration on sculptures and paintings, p. 40.

36 M.J. González, Brocado aplicado, p. 74.

37 J. Nadolny, The gilded tin-relief backgrounds, p. 174 
Hay tres formas básicas en las que el pintor puede crear motivos en tres dimensiones ${ }^{38}$ : 1.- por sustracción (eliminando material de forma selectiva de las capas de preparación); 2.- por deformación (ejerciendo presión con un molde, un punzón o un buril sobre el área a decorar); y 3.- por adición (aplicando material sobre la superficie). Esta última tipología engloba la mayor variedad de técnicas, que se reducen a siete, incluyéndose entre ellas el brocado de estaño en relieve aplicado. La búsqueda de técnicas plástica y visualmente más perfectas, junto con su cronología, son los criterios que definen la evolución de estas siete técnicas en relieve por adición concluyendo con la considerada más detallista, el brocado de estaño en relieve aplicado.

Las primeras decoraciones aplicadas fueron los metales recortados que se emplearon desde el siglo VIII ${ }^{39}$. Uno de los metales más utilizados fue la lámina de estaño cuyo empleo aparece descrito en tratados desde el siglo $\mathrm{IX}^{40}$. Era práctica común utilizar estaño dorado mediante corladura o corla ${ }^{41}$, porque suponía un menor coste económico que emplear lámina de oro.

El papel recortado es una técnica muy similar a la anterior, pero en este caso se emplea tan solo papel ${ }^{42}$.

El relieve a mano alzada empezó a formar parte de las decoraciones pictóricas de esculturas de madera y piedra en el siglo XIII. Los lugares más típicos de aplicación eran los bordes de las indumentarias eclesiásticas. A veces se incluían fragmentos de cristal o cabujones ${ }^{43}$. Ya en el siglo XIV Cennino Cennini en su Tratado de la pintura ofrecía indicaciones sobre cinco procedimientos diferentes de realizar relieve a mano alzada ${ }^{44}$.

38 Idem, The techniques and use of gilded relief decoration, vol. I, p. 47.

39 E. Woolley, J. Nadolny, L. Shekede, Tin relief on thirteenth-century Cypriot wall painting, p. 338.

40 Algunos de los tratados que describen el empleo de la lámina de estaño en la decoración de obras pictóricas y escultóricas son el manuscrito de Lucca (siglo IX), el Mappae Clavicula (siglo XII), el manuscrito del monje Theophilus (siglo XII), el manuscrito de Heraclius (siglo XIII), el Tratado de Pier de Saint Audemar (finales del siglo XIII-principios del siglo XIV) y el Tratado de la pintura o Libro del arte de Cennino Cennini (finales del siglo XIV).

${ }^{41}$ La corla o corladura es un barniz de resinas y esencias, generalmente coloreado, que se aplica sobre láminas metálicas para proporcionar un aspecto metalizado a la superficie. En láminas de plata y estaño es frecuente la presencia de una corla amarillenta para imitar al oro. Véase F.R. Bartolomé, Calvario del Santo Cristo, p. 125.

42 J. Nadolny, The techniques and use of gilded relief decoration, vol. I, p. 43.

43 M. Serck-Dewaide, Relief decoration on sculptures and paintings, p. 36; M. Koller, Zur technologie der pastiglia vom 13. bis 20. jahrhundert.

${ }^{44}$ Cennini se refiere a esta técnica por medio del término genérico de "relieve" y, según la receta, lo define más incluyendo el material con el que dicho relieve está compuesto. Así, por ejemplo, en cada una de las cinco recetas que proporciona para crear relieves a mano alzada utiliza una terminología diferente: relieve con mortero (capítulos CII y CXXVII), relieve de yeso apagado (capítulo CXXIV), relieve con barniz (capítulo CXXIX) y relieve con cera (capítulo CXXX). Véase C. Cennini, El Libro del Arte, pp. 144, 145, 162-166. 
La elevada inversión de tiempo que requería llevar a cabo decoraciones con relieves realizados a mano alzada impulsó a los pintores a mejorar las técnicas de obtención de elementos en relieve por aplicación. La solución se la proporcionó el empleo de la matriz o molde en el proceso de ejecución que a partir de ese momento estuvo presente en las técnicas en relieve por adición.

Basándonos sobre todo en la menor complejidad de la técnica en comparación con las siguientes modalidades que también emplearon matriz, todo apunta a que la primera de estas técnicas que empezó a hacer uso de la matriz fue el relieve moldeado simple. Esta técnica fue la sucesora del lento trabajo propio del relieve a mano alzada y llegó a alcanzar gran éxito en el siglo XIV. La temática característica de esta técnica eran los diseños florales, animales o geométricos. En obras de pintura tendían a localizarse en los fondos, mientras que, en esculturas, se encontraban en los bordes de las vestimentas ${ }^{45}$. Cennini aporta en su tratado una de las más antiguas y completas recetas conservadas hasta la fecha sobre esta tipología pictórica en relieve. Es esta descripción en concreto la que permite conocer con gran precisión esta técnica y distinguirla de otras ${ }^{46}$.

La siguiente técnica que incorporó la matriz en su proceso fue el papel moldeado cuyos primeros ejemplos conocidos datan de principios del siglo XV, aunque alcanzó mayor popularidad en la segunda mitad de dicho siglo $^{47}$. Ésta se puede considerar una variante del relieve moldeado simple, ya que la diferencia más notable se detecta en la mezcla que compone el relieve, en este caso, fragmentos o fibras de papel. En general, los elementos en relieve resultantes eran de pequeño tamaño y gran delicadeza. Los motivos solían ser florales o geométricos y su lugar de aplicación eran los fondos de las ropas ${ }^{48}$. El Libro de Arte de Núremberg (The Nürnberg Kunstbuch) de 1470-1500, escrito por una monja (anónima) del convento dominico de Santa Catalina, Núremberg (Alemania), conserva una receta para realizar papel moldeado ${ }^{49}$.

Las dos últimas técnicas decorativas en relieve por adición que prosiguieron con el empleo de la matriz presentaron un notable progreso en su procedimiento de elaboración. El avance al que nos referimos es la utilización del estaño en lámina. Este material se usaba principalmente como estrato de

45 M. Serck-Dewaide, Décors en relief, p. 91.

46 Cennino Cennini no emplea ningún término específico para designar esta técnica. Sin embargo, se refiere a ella a través de la expresión "modelar relieves", la cual implica el uso de moldes o matrices. Véase C. Cennini, El Libro del Arte, pp. 163, 164.

47 J. Nadolny, The techniques and use of gilded relief decoration, vol. I, p. 336.

48 T. Gómez, Policromía del gótico final, p. 577.

49 Esta receta no incluye ningún término concreto para referirse a la técnica del papel moldeado. En cambio, hace uso de las expresiones "moldear con papel" y "moldear imagen de papel de tres dimensiones". Véase J. Nadolny, Documentary Sources, p. 44. 
soporte de la masa del relieve y como estrato de separación del relieve de la matriz. Esto suponía la obtención de motivos de mayor detallismo y flexibilidad, facilitando su adaptación a la obra y resultando un proceso rápido, económico y eficaz ${ }^{50}$.

La primera técnica que combinó en su ejecución la matriz y el estaño fue el relieve de estaño. Los casos más antiguos de aplicaciones en tres dimensiones que todavía conservan lámina de estaño se localizan en obras datadas en el siglo XIII e incluso antes. Sin embargo, es en el siglo siguiente cuando sufren un auge ${ }^{51}$. El estudio de pinturas que han llegado hasta nuestros días coincide con lo especificado en diversas cuentas de pago de pinturas murales localizadas en Francia (1374-1489) y varias ordenanzas gremiales de pintores del Centro y Norte de Europa (1269-1496): el relieve de estaño era una técnica decorativa para adornar y embellecer pinturas de alta calidad sobre tabla y muro en Francia y las regiones de alrededor durante gran parte de la Baja Edad Media $^{52}$. Este profuso uso de la técnica en la Europa occidental, apoya la reciente hipótesis de su propagación por la geografía europea en sentido oeste-este ${ }^{53}$. El procedimiento no sólo se emplea para obtener elementos decorativos de estaño en relieve aplicables a obras pictóricas, sino también para crear lo que en la bibliografía especializada se denominan "pasteprints" 54 . Las fuentes tradicionales escritas que describen el modo de proceder del relieve de estaño son el Libro del arte de Cennino Cennini de finales del siglo XIV ${ }^{55}$ y el Manuscrito de Tegernsee -también conocido como Liber Illuministarius o Liber Illuministarum - de finales del siglo XV escrito por varios autores ${ }^{56}$. En las publicaciones contemporáneas sobre el tema estas dos fuentes son

50 Idem, The gilded tin-relief backgrounds, p. 183.

51 Idem, The techniques and use of gilded relief decoration, vol. I, pp. 7-10.

52 Idem, Documentary Sources, p. 42.

53 E. Woolley, J. Nadolny, L. Shekede, Tin relief on thirteenth-century Cypriot wall painting, p. 338.

${ }_{54}$ Estos elementos consisten en imágenes de bajo relieve adheridas a papel utilizadas en la ornamentación de libros durante la segunda mitad del siglo XV. Los análisis químicos llevados a cabo sobre "pasteprints" (grabados sobre pasta) corroboran que su estructura, materiales y apariencia son iguales a las estudiadas en los relieves de estaño. Véase C.L. Bowman, Pasteprints, pp. 4, 11; J. Nadolny, The techniques and use of gilded relief decoration, vol. I, pp. 86-87.

55 En su tratado, Cennino Cennini dedica dos capítulos a describir el procedimiento a seguir para crear motivos de relieve de estaño sobre diferentes soportes, sin aportar una terminología precisa para referirse a la técnica o motivos resultantes. Así pues, en el primer capítulo sobre esta decoración (capítulo CXXVIII) emplea la expresión "relieves con molde de piedra" la cual no abarca una característica fundamental de la técnica que es el empleo de estaño. En el siguiente capítulo (capítulo CLXX) utiliza un término más preciso y completo: "figuras de estaño". Véase C. Cennini, El Libro del Arte, pp. 165, 210.

56 En este manuscrito se usa "hoja de estaño" para designar tanto la hoja de estaño propiamente dicha como la técnica y motivos de relieve de estaño. Asimismo, no aporta ningún dato sobre la naturaleza de la matriz. Véase M.J. González, Brocado aplicado, pp. 71, 72; 
consideradas como las primeras descripciones del brocado de estaño en relieve aplicado. Dado que ninguna de estas dos fuentes documentales se refiere a la producción de motivos textiles (temática propia del brocado de estaño en relieve aplicado) no es posible confirmar que se trate de los procedimientos que los antiguos artesanos seguían para la fabricación del brocado de estaño en relieve aplicado. No obstante, es muy probable que el proceso de ejecución de dicha técnica fuera muy similar al contenido en estos dos tratados.

Según los estudiosos del tema la última y más detallista técnica en relieve por adición fue el brocado de estaño en relieve aplicado. Consistía en una modificación fundamentalmente estilística del relieve de estaño que mantuvo sin grandes variantes el proceso de ejecución, pero que experimentó cambios en las composiciones materiales de algunos estratos ${ }^{57}$. El cambio en las prioridades estilísticas estuvo provocado por la pasión por imitar la apariencia de los suntuosos tejidos de los siglos XV y XVI realizados en terciopelo y seda decorados con brocados hechos de hilos de oro y plata ${ }^{58}$. En consecuencia, al valor artístico de la técnica hay que añadirle su interés como documento histórico ${ }^{59}$.

A pesar de que algunos estudiosos piensen que el brocado de estaño en relieve aplicado se utilizaba normalmente para la ornamentación de los ropajes de los personajes principales representados en las obras ${ }^{60}$, su ámbito de aplicación era mucho más amplio. En realidad, puesto que el tipo de aplicación que nos ocupa reproducía los lujosos textiles brocados de la época, se incluía en todas aquellas zonas susceptibles de estar cubiertas por telas y en todas aquellas que en la sociedad de entonces se decoraban: tanto las vestiduras y accesorios como los paramentos litúrgicos y elementos ornamentales de los hogares. Las referencias documentales muestran un extenso abanico de posibilidades de ubicación de esta decoración tridimensional sobre la superficie de las obras de arte: fondos, fondos a imitación de tejidos brocados como si de tapices colgantes se tratara, vestimentas de las figuras, peanas, bancos, cojines, baldaquinos y colchas de cama, entre otros.

La definición del origen temporal y geográfico del brocado de estaño en relieve aplicado ha sido muy analizada en las fuentes documentales. Debido, fundamentalmente, a la incalculable pérdida de numerosas obras de arte de la Baja Edad Media en países del Norte de Europa con motivo de importantes

J. Nadolny, The techniques and use of gilded relief decoration, vol. I, p. 344; A. Bartl et al., Der "Liber illuministarum" aus Kloster Tegernsee.

57 J. Nadolny, The techniques and use of gilded relief decoration, vol. I, pp. 355-361.

58 J.A. Darrah, White and Golden Tin Foil, p. 61.

59 Equipo 7 Restauración, Proceso de restauración del retablo mayor del Santuario de la Encina, p. 51. p. 382 .

60 I. Berasain, M.T. Barriola, Aproximación a la policromía del Retablo de San Antón, 
períodos de iconoclasia, no es posible establecer con exactitud dicho origen. Sin embargo, a partir del patrimonio artístico que ha llegado hasta nuestros días, en la última década varios especialistas han intentado arrojar luz sobre este tema. Cronológicamente, las investigaciones más recientes sitúan los primeros ejemplos de brocado de estaño en relieve aplicado en el espacio de tiempo comprendido entre 1415 y 1425 . Tal afirmación queda justificada por medio de cinco obras consistentes en pinturas sobre tabla con aplicaciones en relieve parejas a la técnica y motivos del brocado de estaño en relieve aplicado ${ }^{61}$.

Todos los autores que se refieren al lugar de origen siempre sugieren los antiguos Países Bajos ${ }^{62}$ o más concretamente la región de Flandes ${ }^{63}$. Teniendo presente los últimos estudios sobre las obras más antiguas que aún perviven, se han identificado entre las ubicaciones geográficas originarias, los Países Bajos, Colonia, Berlín, Hamburgo y Norwich. Por consiguiente, y basándonos en la documentación más actualizada, las creencias sobre el origen geográfico del brocado de estaño en relieve aplicado han de ampliarse e incluir, además de los Países Bajos, Alemania e Inglaterra.

\subsection{Período de uso}

El disperso empleo de la técnica en sus orígenes propició por medio de diversos canales su propagación hacia otras zonas de la geografía europea: España, Portugal, Francia, Suiza, Austria, Lombardía, Bohemia, Suecia

61 Estas cinco obras a las que nos referimos son: el Tríptico de la Crucifixión Dominica de la Escuela de Colonia (circa 1420/5-1430; aunque existen muchas controversias con respecto a la fecha de ejecución), Museo Wallraf Richartz, Colonia; los paneles (tres) de la Crucifixión, la Anunciación y Santa Margarita y el Dragón (circa 1415-1430; también se propone circa 1450 o circa 1450-1475) de un altar de la iglesia parroquial de St. Michael at Plea, Norwich (desde 1954 están conservados en la Catedral de Norwich); el panel de La Virgen Alemana y Cristo Niño con un Tintero (circa 1420), Gemäldegalerie, Berlín; el panel de Cristo como el Hombre de los Dolores del Maestro Francke (circa 1320-1340. Sin embargo, el análisis dendrocronológico de la madera del panel revela una fecha de ejecución posterior, circa 1431, la cual encajaría mejor con las fechas de datación de las obras previas y, por consiguiente, con el período de tiempo propuesto para el nacimiento de la técnica del brocado de estaño en relieve aplicado. Asimismo, también se apunta la fecha de circa 1435), iglesia parroquial de St. John, Hamburgo (desde 1924 pertenece a la colección del Kunsthalle, Hamburgo); alas del Retablo de la Pasión (circa 1420-1425), iglesia de St. Reinold, Dortmund (se trata de un retablo importado y ejecutado en los antiguos Países Bajos). A pesar de ser consideradas las primeras obras con brocados de estaño en relieve aplicados, dichos motivos no se restringen a la decoración de un único tipo de elemento, sino que se localizan en diferentes zonas de las obras: las vestimentas (Colonia y Berlín) y las telas del fondo (Hamburgo y Norwich). Véase J. Nadolny, The techniques and use of gilded relief decoration, vol. I, pp. 82, 324 y vol. II, pp. 95-110, 133-144, 301, 302; I. Geelen, D. Steyaert, Imitation and Illusion, pp. 49, 50, 62.

62 M.J. González, Brocado aplicado, p. 67.

${ }_{63}$ T. Gómez, Policromía del gótico final, p. 576; L.F. Jacobs, Early Netherlandish carved altarpieces, 1380-1550, p. 82. 
y Gales ${ }^{64}$. Su difusión hizo que se convirtiera en una técnica decorativa muy popular en Europa en la producción de arte a partir de mediados del siglo $\mathrm{XV}^{65}$.

En lo que respecta a España, la técnica en cuestión se introdujo en el ecuador del siglo $\mathrm{XV}^{66}$. La vía de entrada fue la importación de numerosos trípticos de estilo gótico ejecutados por esas mismas fechas en los antiguos Países Bajos meridionales, algunas zonas de Alemania, parte del norte de Francia e incluso la Borgoña ${ }^{67}$. Este canal se vió incrementado hacia el primer tercio del siglo XVI con la llegada de los artistas foráneos de Europa del Norte que conocían el brocado de estaño en relieve aplicado y lo utilizaban en las obras del tardogótico español ${ }^{68}$. Paulatinamente y de forma paralela, los pintores autóctonos fueron asimilando e interpretando de acuerdo a su estilo pictórico este tipo de decoración que fueron incorporando en sus obras $^{69}$.

El foco originario de este procedimiento en España fue Burgos. En el siglo XV, el entonces gran puerto de Brujas -éste y el puerto de Amberes eran dos de los más poderosos centros de producción de arte y comercio de los siglos XV y XVI de Flandes- extendió su tráfico hacia las costas del golfo de Vizcaya y los puertos del Cantábrico, favoreciendo el comercio entre los dos países. Como es sabido, los puertos cantábricos pertenecían a la diócesis burgalesa, cuya sede episcopal era una de las más ricas de la península y del reino de Castilla. La constitución de esta vía marítima superó a la ruta terrestre, la del Camino de Santiago, en la formación de un Burgos mercantil. De este modo, los puertos vascos de Álava, Vizcaya y Guipúzcoa, entre los que destaca Bilbao, que, con su ría, llegó a ser el puerto más activo de Burgos, se convirtieron en piezas clave del discurrir del comercio castellano y de la entrada de las primeras obras de arte flamenco, muchas de ellas decoradas con brocados de estaño en relieve aplicados. Por consiguiente Burgos absorbió gran parte de las obras importadas así como de los artistas foráneos inmigrantes, funcionando como foco de irradiación del modelo pictórico flamenco y, por supuesto, del brocado de estaño en relieve aplicado, que, desde allí, se debieron de difundir al resto del país y también Portugal, dado el descubrimiento

64 J.A. Darrah, White and Golden Tin Foil, p. 62; M.J. González, Brocado aplicado, p. 67.

${ }_{65}$ A. Rodríguez, Decoración polícroma en relieve. El brocado aplicado, p. 66; I. Geelen, D. Steyaert, Imitation and Illusion, p. 49.

66 R. García, E. Ruiz de Arcaute, Aproximación al brocado aplicado en España, p. 751.

67 J. Muñiz, Reflejos de Flandes, p. 48.

68 H.E. Wethey, Gil de Siloe and his school, pp. 4-6; P.L. Echeverría, El retablo en el País Vasco, vol. I, p. 77.

69 J. Muñiz, El retablo gótico esculpido, vol. I, pp. 129-135; idem, Reflejos de Flandes, pp. 177, 178; I. Geelen, D. Steyaert, Imitation and Illusion, pp. 61, 62. 
cada vez más común de obras con motivos de brocado de estaño en relieve aplicado en ambos países ${ }^{70}$.

Como previamente se ha apuntado, el brocado de estaño en relieve aplicado es una variante principalmente estilística de la técnica y los materiales empleados en las decoraciones de relieve de estaño. Esto queda confirmado a través de la localización y estudio de múltiples ejemplos de relieve de estaño en diversos países de Europa, a diferencia de España, donde las escasas evidencias de este tipo de técnica ${ }^{71}$ parecen indicar que los motivos de brocado aplicado de estaño tuvieron en las obras de arte norteeuropeas su primera y más importante fuente de inspiración.

La época de decadencia del brocado de estaño en relieve aplicado tuvo lugar, en general, en toda Europa a mediados del siglo XVI. Por lo tanto, se puede decir que la vigencia de este procedimiento tridimensional abarcó un siglo - de mitad del siglo XV a mitad del siglo $\mathrm{XVI}^{72}$.

El período de tiempo tan concreto en el que se mantuvo vigente este tipo de decoración permite en la actualidad datar las obras decoradas con ella.

Frente a la aparición del novedoso sistema del brocado de estaño en relieve aplicado, los artistas no se detuvieron y continuaron buscando mejoras tecnológicas que les supusieran ventajas orientadas a la reducción del tiempo de producción, los materiales pictóricos y los gastos económicos. De este modo surgió una técnica más rápida que lentamente llegó a sustituir al brocado de estaño en relieve aplicado. Se trata del esgrafiado ${ }^{73}$.

El esgrafiado consiste en imitar los tejidos ricos de aquel período aplicando una capa de pintura sobre una superficie de oro bruñido y con un elemento en punta raspar el color formando líneas y motivos para que se descubra el oro $^{74}$.

Esta técnica pictórica parece que empezó a emplearse tiempo antes en Italia, pero no experimentó un importante desarrollo hasta el inicio del si-

70 E. Bermejo, La pintura de los primitivos flamencos en España, vol. I, pp. 11, 26, 31, 32; J.A. Barrio, El Retablo Mayor del Santuario de la Encina de Arceniega en Álava, pp. 6, 50; T. Gómez, Policromía del gótico final, p. 576; J. Muñiz, Reflejos de Flandes, pp. 191, 192.

71 Hasta el presente la única obra de procedencia española en la que se ha identificado el uso de aplicaciones de relieve de estaño es el Antependium de Escuela Catalana datado en 1250 y conservado en el Walters Art Museum, Baltimore, Estados Unidos. En concreto, este frontal de altar consiste en una pintura sobre tabla decorada, entre otros, con motivos sueltos de relieve de estaño a lo largo de todo su perímetro y en el contorno de la mandorla del Cristo. Véase J. Nadolny, The techniques and use of gilded relief decoration, vol. I, pp. 212, 213 y vol. II, pp. 205-214.

72 M. Serck-Dewaide, Décors en relief, p. 91.

73 T. Gómez, El Retablo Mayor de la Catedral de Toledo, vol. II; I. Geelen, D. Steyaert, Imitation and Illusion, p. 65.

74 M.E. Gómez, La policromía en la escultura española, p. 16. 
glo XVI en los talleres de Amberes. Esto se debió a que, a partir de 1500, los talleres ubicados en Bruselas (una de las localidades donde más se desarrolló y usó el brocado de estaño en relieve aplicado durante la segunda mitad del siglo $\mathrm{XV}$ ) descendieron en reputación e índices de producción, siendo reemplazados por los gremios de Amberes y su preferencia por la técnica del esgrafiado ${ }^{75}$.

Este mismo tipo de decoración se estaba empleando en España en los últimos años del siglo XV. Sin embargo, igual que sucedió en Amberes, su utilización no comenzó a imponerse y hacerse más habitual hasta principios del siglo siguiente, cuando se produjo una disminución del uso del brocado de estaño en relieve aplicado.

A medida que en Europa fue dejando de usarse el brocado de estaño en relieve aplicado se fue instaurando el esgrafiado, el cual, finalmente, logró triunfar hacia la mitad del siglo $\mathrm{XVI}^{76}$.

\subsection{Artífices}

Al detenernos a analizar el tipo de profesional y el oficio del que se ocupaba de realizar y aplicar esta tipología de decoración hemos descubierto que hasta la fecha apenas existe información alguna al respecto.

Se ha sugerido que el hacedor de todo el proceso de elaboración de los brocados de estaño en relieve aplicados (desde la matriz hasta la aplicación de los motivos) era el propio maestro pintor o un policromador, incluso un artesano específico experto en dicha labor y externo al taller del pintor, o quizás un escultor, grabador u orfebre especializado en producir matrices, que era subcontratado por el taller del pintor para que éste se proveyera de matrices a partir de las que reproducir los motivos de brocado en estaño ${ }^{77}$. Sin embargo, si tenemos en cuenta, por un lado, que todos los motivos pictóricos practicados en una misma obra eran propiedad del taller del pintor encargado de su policromía y, por otro lado, que en más de un retablo se ha podido constatar la presencia de los mismos motivos textiles ejecutados con diferentes técnicas pictóricas, entre las que se encuentra el brocado de estaño en relieve aplica$\mathrm{do}^{78}$, llegamos a la conclusión de que el responsable de la ejecución de esta técnica era alguien que participaba en los quehaceres del taller del pintor. Por

75 Ibidem, p. 16; M. Serck-Dewaide, The history and conservation, p. 70; idem, Support and Polychromy of Altarpieces, pp. 88, 90.

76 T. Gómez, Policromía del gótico final, pp. 577, 579.

77 M.S. Frinta, The use of wax for applique relief brocade on wooden statuary, p. 143; J.A. Darrah, White and Golden Tin Foil, p. 62; I. Geelen, D. Steyaert, Imitation and Illusion, p. 69.

78 H. Westhoff et al., Graviert, gemalt, gepresst, pp. 565, 566. 
consiguiente, todo parece indicar que los diseños de los brocados de estaño en relieve aplicados pertenecían al taller de un pintor concreto y, en consecuencia, su hacedor también tenía que pertenecer al mismo taller para poder disponer de esos diseños específicos.

En la España de finales del siglo XV y siglo XVI, los talleres de pintura se dividían en dos especialidades: las relativas y las no relativas a los retablos. Dentro de las primeras se encontraban los pintores de retablos y los doradores. Los primeros se encargaban del estofado, el encarnado y el pintado en general, mientras que los segundos se limitaban al dorado ${ }^{79}$. Al plantearnos cuál de estos dos especialistas del taller del pintor se encargaba de la ejecución y aplicación de los motivos de brocado de estaño en relieve aplicado, y teniendo presente las escasas referencias bibliográficas sobre el tema, únicamente se han podido extraer las siguientes dos hipótesis.

La primera hipótesis hace pensar que, dentro del taller del pintor, ni el pintor ni el dorador de retablos se ocupaba de los brocados de estaño en relieve aplicados y que era otro artesano el que se dedicaba a su elaboración, aplicación y acabado final sobre cualquier tipo de obra, así como a otra serie de tareas. Esta suposición está basada en parte en la creencia que asigna dicho papel al aprendiz o aprendices del maestro pintor ${ }^{80}$, ya que el proceso de producción de estas decoraciones volumétricas era mecánico y seriado sin involucrar grandes habilidades manuales. Muy posiblemente, por tratarse de un trabajo tan automático y al alcance de las aptitudes de los miembros menos formados del taller (los aprendices), los pintores e incluso los doradores no lo consideraban a su altura y, por lo tanto, lo dejaban en manos de los menos experimentados. Esta suposición explicaría la abundancia de piezas de brocado de estaño en relieve aplicado en obras de nuestro país, puesto que, si resulta ser cierto que era un procedimiento relativamente sencillo realizado por aprendices, es presumible que no fuera una técnica de alto coste económico y de ahí su profusa utilización.

La segunda y más reciente hipótesis sobre el responsable del brocado de estaño en relieve aplicado se basa, por un lado, en dos de las primeras y más antiguas ordenanzas gremiales de pintores que mencionan este tipo de decoración ${ }^{81}$, las Ordenanzas de Tournai (Bélgica) de 1480 y las Ordenanzas

79 R. Bruquetas, A. Carrassón, T. Gómez, Los retablos. Conocer y conservar, p. 17.

80 J.A. Darrah, White and Golden Tin Foil, p. 62.

${ }^{81}$ Las ordenanzas de pintores más antiguas que mencionan la técnica del brocado de estaño en relieve aplicado pertenecen a ciudades del Centro y Norte de Europa: las Ordenanzas de Londres (Inglaterra) de 1466, las Ordenanzas de Amberes (Bélgica) de 1470, las Ordenanzas de Tournai (Bélgica) de 1480, las Ordenanzas de Constanza (Alemania) de aproximadamente 1495 y las Ordenanzas de Lyon (Francia) de 1496. Véase J. Nadolny, The techniques and use of gilded relief decoration, vol. I, pp. 333, 334. 
de Constanza (Alemania) de aproximadamente 1495, y, por otro lado, en un contrato suizo para la ejecución de un retablo: Berna, Contrato para un retablo $(1501)^{82}$. Los tres documentos se refieren, con mayor o menor detalle, a la ejecución de motivos textiles en relieve por parte del (maestro) dorador y policromador $^{83}$ (Ordenanzas de Tournai, 1480 y Contrato de Berna, 1501) y del dorador (Ordenanzas de Constanza, circa 1495). Se extrae la conclusión de que, por término general, tanto el dorador como el policromador tenían que saber desempeñar las mismas tareas, si bien es cierto que las funciones descritas en los tres documentos son las propias de un dorador: aplicación de la preparación, punzonado ${ }^{84}$, embolado o aplicación del bol, dorado y bruñido y, por último, se incluye la realización y adhesión de brocados de estaño en relieve aplicados ${ }^{85}$. En consecuencia, el análisis del contenido de estos documentos nos induce a pensar que era más concretamente un artesano especializado en las labores características de un dorador el responsable artífice de los motivos de brocado de estaño en relieve aplicado, al menos, en los países referidos, a finales del siglo XV y principios del siglo XVI.

Si comparamos las dos hipótesis observamos que no son del todo contradictorias dado que, mientras la primera adjudica la producción de estos relieves textiles al aprendiz o aprendices del taller del pintor, la segunda lo hace a artesanos con amplios conocimientos en dorado que igualmente pertenecen al taller del pintor. De una parte, los aprendices ocupaban uno de los más bajos rangos dentro del taller del pintor por dedicarse a múltiples tareas debido a su todavía escasa especialización en una labor concreta. De otra parte, la actividad de los doradores era considerada un estadio más bajo del aprendizaje que la de los pintores de retablos hasta avanzado el siglo $\mathrm{XVI}^{86}$. Esto supone que, en cualquiera de los dos casos, las piezas de brocado de estaño en relieve aplicado

82 Idem, One craft, many names, vol. I, pp. 11, 13.

83 El término policromador alude al pintor de retablos, puesto que en las Ordenanzas de Tournai se hace clara distinción entre el que realiza la obra de pintura (oevre de pourtraiture) -el pintor- y el que realiza la obra de dorado y policromado (oevre de dorer et estoffer) -el dorador y policromador o pintor de retablos. Véase ibidem, p. 13.

84 Tal como se ha mencionado más arriba al describir las tres formas básicas en las que el pintor puede crear motivos en tres dimensiones, el punzonado es el procedimiento por medio del cual se obtienen decoraciones en bajo relieve en la preparación y que de acuerdo a Nadolny recibirían la denominación de relieves obtenidos por deformación en seco. Véase idem, The techniques and use of gilded relief decoration, vol. I, p. 47.

85 La terminología empleada en las dos ordenanzas y el contrato de retablo para referirse a la técnica pictórica del brocado de estaño en relieve aplicado es variada: draps d'or (Ordenanzas de Tournai, 1480), kamkatt (Ordenanzas de Constanza, circa 1495) y kamkat (Contrato de Berna, 1501). Véase idem, One craft, many names, vol. I, p. 13. Para una detallada discusión sobre la traducción de los términos véase idem, The techniques and use of gilded relief decoration, vol. I, pp. 338-340, 342-344.

86 R. Bruquetas, A. Carrassón, T. Gómez, Los retablos. Conocer y conservar, p. 17. 
eran creadas y aplicadas en las obras por artesanos de menor categoría profesional que los pintores de retablos y nunca por el maestro pintor, ateniéndonos a la falta de evidencias documentales que confirmen lo contrario. Esta hipótesis final se puede hacer extensible a toda Europa, incluyendo España, puesto que no contradice de ningún modo la división de tareas del taller del pintor de la época en nuestro país ni la documentación hallada sobre el tema.

Centrándonos en los posibles artífices, con nombre y apellido, que se encargaron de la ejecución de los motivos de brocado de estaño en relieve aplicado que todavía se conservan en una gran variedad de retablos dispersos por la geografía española, podemos comenzar apuntando que, partiendo de la base de que su producción tenía lugar en los talleres de pintores, sabemos que en el siglo $\mathrm{XV}$ se crearon en Burgos unos talleres de pintura y escultura que se convirtieron en modelo y guía de la producción artística hasta bien entrado el siglo XVI.

En general, gran parte de las obras escultóricas (retablos fundamentalmente) de este período en nuestro país no están bien documentadas, lo que se traduce en grandes lagunas en las atribuciones de la parte escultórica y pictórica. De los pocos ejemplos que conservan su documentación original, la gran mayoría sólo deja constancia de los escultores y no de los policromadores ni de los doradores y mucho menos de los hacedores de brocados de estaño en relieve aplicados, mientras que una minoría incluye las autorías de los escultores y los policromadores. En este último caso y, en especial en las piezas datadas en el siglo XV, coinciden (como es de esperar atendiendo al estilo artístico flamenco predominante en esa época en Castilla) escultores y policromadores de origen norteuropeo.

A pesar de la escasez de datos mencionada, son los pintores que aparecen documentados en retablos con brocado de estaño en relieve aplicado emplazados dentro de España, los que más nos pueden acercar a los auténticos artífices de esta singular técnica decorativa. Entre estos pintores se encuentran Diego de la Cruz, León Picardo, Juan de Borgoña, Francisco de Espinosa, Alonso de Salamanca, Jacome de Lobeo, Diego de Torres, Juan García de Crisal, Chordón, Andrés de Espinosa y Juan Martínez de Olazarán. Probablemente también Lope Lorenzo y Martín Ochoa de Irazábal ${ }^{87}$.

Un estudio más pormenorizado de este grupo de pintores, revela que hubo un predominio de pintores locales en el territorio vasco en contraposición a la supremacía de los pintores norteuropeos que, atraídos principalmente por la riqueza de Burgos, acapararon sobre todo las regiones del interior de la península.

87 R. García, E. Ruiz de Arcaute, El “brocado aplicado”, una técnica de policromía centroeuropea en Álava, pp. 412-414. 


\section{TIPOLOGÍAS Y TEMÁTICAS}

El variado repertorio de motivos de brocado de estaño en relieve aplicado que hoy en día nos podemos encontrar en obras de arte de toda Europa, surgió directamente de los lujosos textiles brocados de los siglos XV y XVI.

Dado que cada taller de pintura tenía su repertorio individual de motivos es muy importante recoger y clasificar de acuerdo a la técnica pictórica todos los motivos de aquellas obras documentadas -es decir, datadas y atribuidas- y no documentadas. Esta base de datos será una herramienta de gran valor para comparar y relacionar motivos y conocer más acerca de los talleres y artesanos que los emplearon y también ayudará a atribuir y datar aquellas obras no documentadas ${ }^{88}$. En España, durante la última década, el registro sistemático de un substancial número de motivos de brocado de estaño en relieve aplicado ha contribuido en las dataciones y atribuciones de varias obras del patrimonio histórico-artístico español ${ }^{89}$.

Concretamente, los motivos de brocado de estaño en relieve aplicado presentan dos tipologías: yuxtapuesto o continuo y suelto o aislado. Estas dos tipologías, así como el repertorio de motivos que se presenta a continuación, se localizan en obras de arte, principalmente retablos de madera, ubicados dentro y fuera de España.

\subsection{Motivos yuxtapuestos}

El brocado de estaño en relieve aplicado yuxtapuesto imita tejidos con decoración uniforme. Para lograr esa uniformidad utiliza varias piezas de brocado con el mismo motivo que gracias a su forma cuadrada o rectangular permite que se yuxtapongan creando una decoración continua sin separaciones entre ellas.

Los tipos de diseño más comunes son los vegetales que conjugan hojas y flores y a veces frutos. Éstos se combinan trazando composiciones más o menos complejas que forman recorridos irregulares o simétricos en torno a un eje vertical (fig. 2). Entre las especies vegetales apreciamos plantas como el cardo, el lis, el loto y el acanto. Las flores se representan a modo de alcachofas o garchofas. Los frutos suelen ser granadas o piñas $^{90}$.

88 H. Westhoff et al., Graviert, gemalt, gepresst, pp. 565, 566.

89 R. García, E. Ruiz de Arcaute, El "brocado aplicado", una técnica de policromía centroeuropea en Álava, pp. 420, 421; A. Rodríguez, Análisis y clasificación de los brocados, pp. $163,164,169$.

90 T. Gómez, Policromía del gótico final, pp. 576-577. 
Dentro de la temática vegetal cabe destacar la decoración vegetal geometrizada donde los motivos aparecen contenidos dentro de formas geométricas ${ }^{91}$.

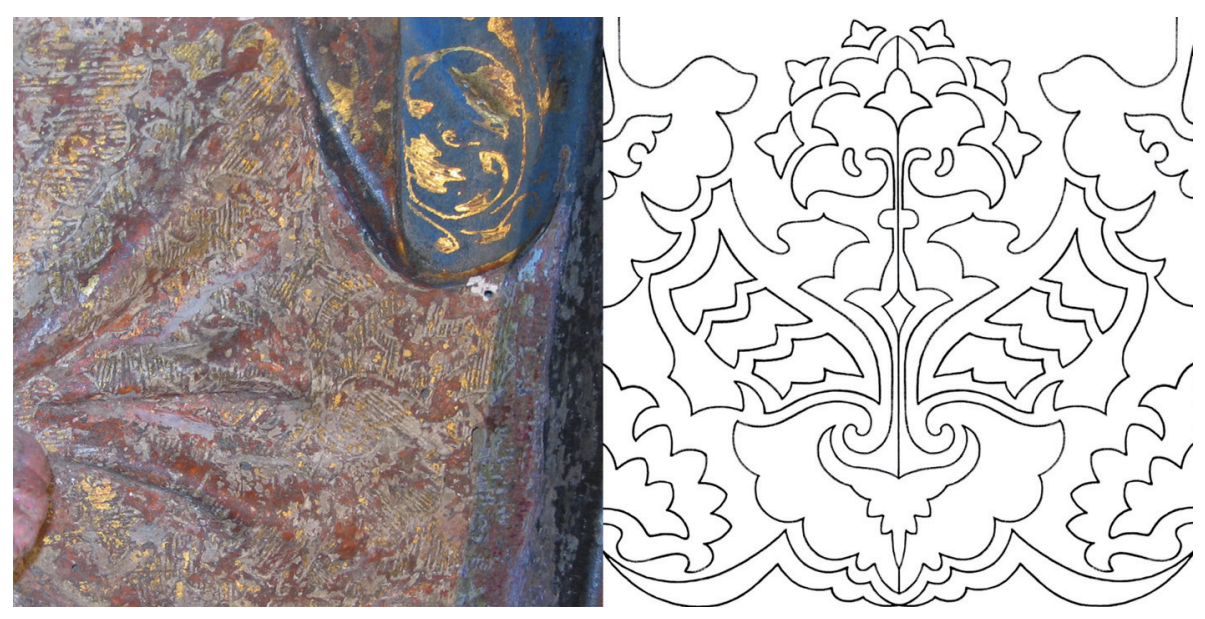

Fig. 2. Diseño vegetal de brocado de estaño en relieve aplicado yuxtapuesto localizado en el retablo de la Santísima Trinidad: (izquierda) fotografía digital; (derecha) reproducción virtual del diseño. Dimensiones (reales): 10x10 cm.

Otro modelo que se repite con cierta frecuencia es el de tipo vegetalanimal. Las composiciones más sencillas incluyen roleos no enrevesados de hojas y flores entre cuyas curvas se desarrollan granadas y animales de líneas sencillas ${ }^{92}$. Las más complicadas responden a la categoría de motivo candelieri. El esquema principal lo trazan brazos zigzagueantes de vegetación de los que surgen sinuosas hojas, flores y frutos formando una red en la que se entretejen figuras fantásticas como monstruos marinos y expresivos rostros humanos (fig. 3) ${ }^{93}$.

91 J.A. Barrio, El Retablo Mayor del Santuario de la Encina de Arceniega en Álava, pp. 56, 58; F.R. Bartolomé, Calvario del Santo Cristo, pp. 40, 72.

92 K.-W. Bachmann, E. Oellermann, J. Taubert, The conservation and technique, p. 355.

93 R. García, E. Ruiz de Arcaute, The conservation and restoration of the polychrome sculpture in Álava, p. 86. 


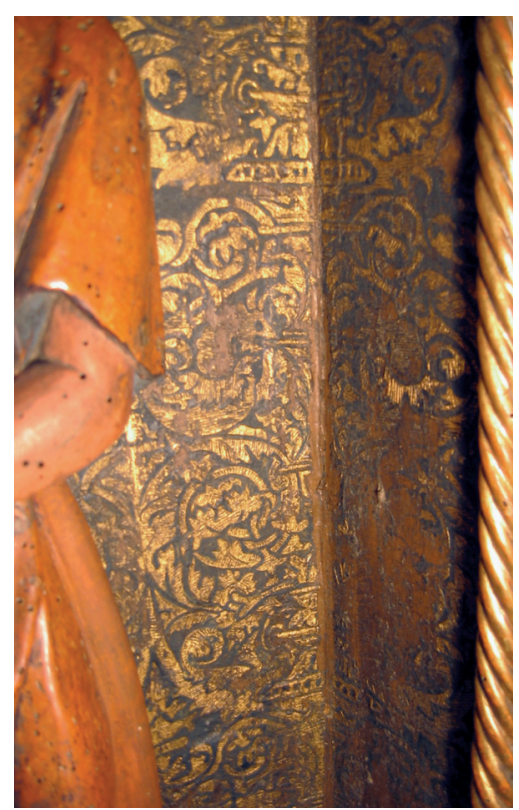

Fig. 3. Fondo de un relieve decorado con brocados de estaño en relieve aplicados yuxtapuestos de temática candelieri-grutesco. Tríptico de San Antón. 1510-1515. Parroquia de San Pedro Apóstol, Zumaya (Guipúzcoa).

Puntualmente se han localizado brocados yuxtapuestos con dibujos geométricos.

Dentro de la tipología continua podemos incluir aquellos motivos compuestos por tiras o bandas que unidas reproducen un diseño repetitivo a modo de cenefa generalmente de temática vegetal ${ }^{94}$. Suelen decorar los bordes de vestimentas y fondos de escenas. A pesar de que raramente se encuentran letras entre los temas de los brocados de estaño en relieve aplicados, es destacable el hallazgo de un diseño continuo en forma de cenefa con letras adornando los remates superiores de los fondos de dos escenas y el borde inferior de una vestidura del retablo mayor de la iglesia de San Juan Bautista, del primer tercio del siglo XVI, en la localidad de Obécuri, Condado de Treviño, Burgos. Debido al estado avanzado de deterioro con importantes pérdidas de todos los estratos, no ha sido posible recoger al completo el motivo ni descifrar el contenido escrito del mismo ${ }^{95}$.

94 I. Geelen, D. Steyaert, Imitation and Illusion, p. 77.

95 A. Rodríguez, F. Bazeta, M.T. Escohotado, El "brocado de estaño en relieve aplicado", p. 302; M. Luciañez, Catalogación y estudio del Brocado Aplicado, pp. 89 y ss. 


\subsection{Motivos sueltos}

El brocado de estaño en relieve aplicado suelto tiende a imitar los bordados sobrepuestos a los tejidos. Así, las piezas de brocado se disponen de forma aleatoria sobre la superficie creando un espacio salpicado de aplicaciones de brocados que repiten el mismo diseño o combinan diseños diferentes.

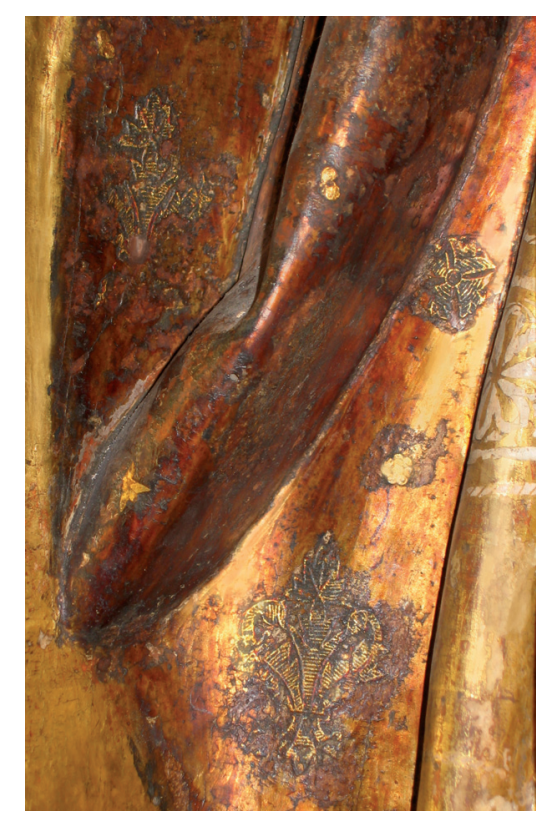

Fig. 4. Reverso del manto de una figura adornado con brocados de estaño en relieve aplicados sueltos. Retablo de la Piedad. 1535-1537. Parroquia de San Miguel Arcángel, Oñate (Guipúzcoa).

Abundan los brocados sueltos de tema vegetal. Pueden adoptar formas simples de hojas o de flores con variantes en el número de pétalos ${ }^{96}$. Ejemplos de brocados vegetales sencillos se observan en la figura 4 donde se incluyen tres brocados combinados con pequeñas aplicaciones de papel: uno de pequeñas dimensiones (fig. 5 , izda.) y otros dos de mayores medidas que reproducen el mismo motivo (fig. 6). Los motivos sueltos también pueden dibujar granadas y follaje de intrincados contornos. Además pueden encontrarse inscritos en formas geométricas ${ }^{97}$.

96 T. Gómez, Policromía del gótico final, p. 576.

97 M. Luciañez, Catalogación y estudio del Brocado Aplicado, pp. 33, 43, 62. 


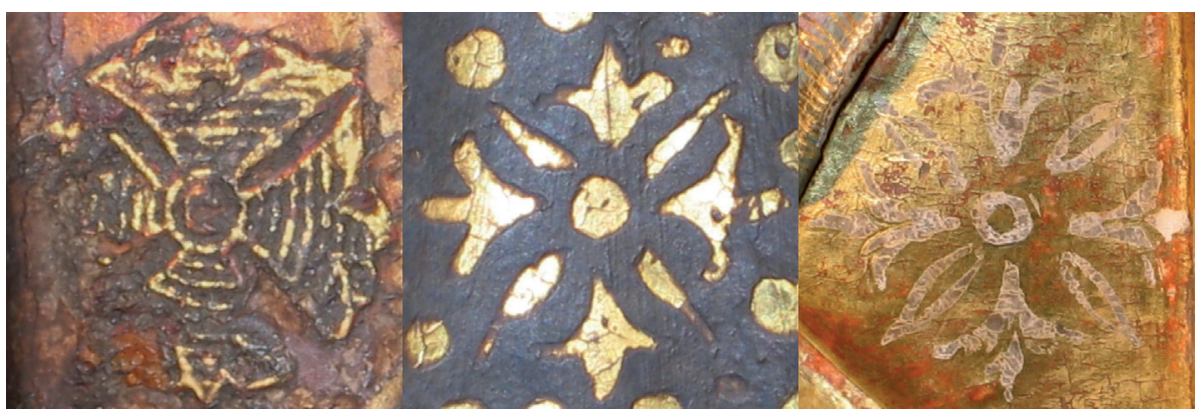

Fig. 5. Mismo diseño reproducido con tres técnicas pictóricas diferentes (de izquierda a derecha): brocado de estaño en relieve aplicado suelto, esgrafiado y estofado. Retablo de la Piedad.
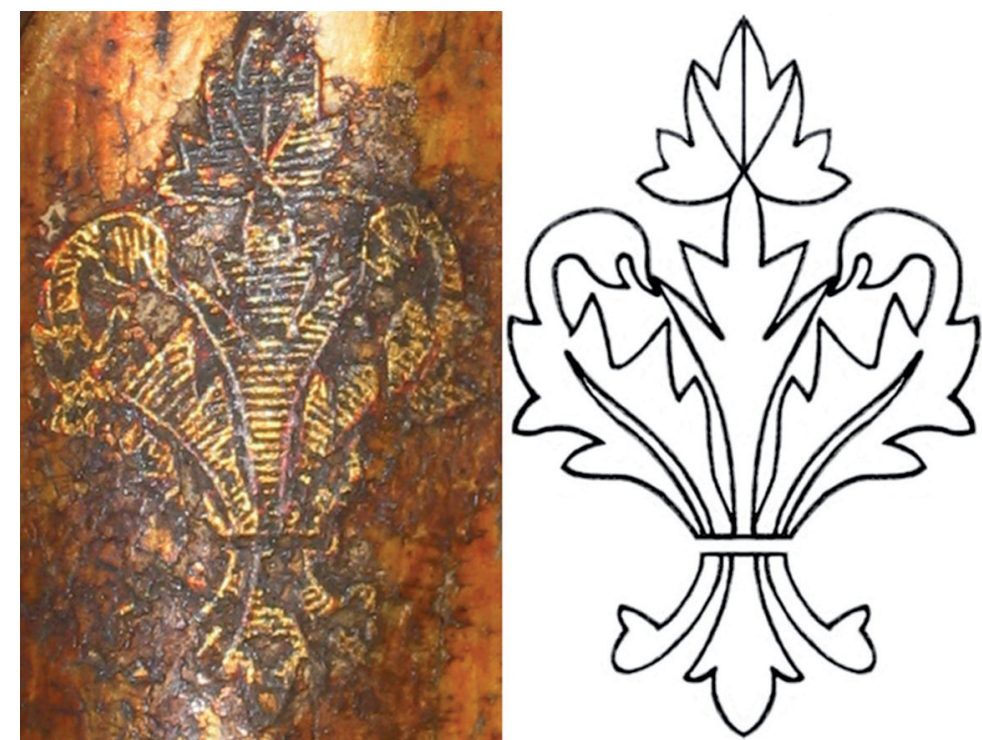

Fig. 6. Diseño vegetal de brocado de estaño en relieve aplicado suelto localizado en el retablo de la Piedad: (izquierda) fotografía digital; (derecha) reproducción virtual del diseño. Dimensiones (reales): 4,4x2,9 cm.

La tipología de modelo animal más recurrente es la del águila ${ }^{98}$, en ocasiones presentando una silueta más compleja que representa a un águila bicéfala ${ }^{99}$.

98 M. Serck-Dewaide, Support and Polychromy of Altarpieces, p. 85.

99 A. Ballestrem, Un témoin de la conception polychrome, pp. 42, 45. 

trella ${ }^{100}$.

Una figura descubierta con frecuencia en varios retablos es la es-

En ocasiones los brocados sueltos son motivos recortados de piezas de mayor tamaño de brocados yuxtapuestos que recogen formas aisladas de temática vegetal, animal, geométrica o una combinación de varias. Los motivos sueltos así como los yuxtapuestos de donde se extraen los primeros se han encontrado dentro de un mismo retablo o en retablos diferentes, contribuyendo, en este último caso, a la atribución de ambos.

\section{CONCLUSIÓN}

La recopilación de las fuentes documentales ha resultado en un mayor conocimiento histórico, artístico y estilístico de la cada vez más abundante técnica decorativa del brocado de estaño en relieve aplicado en el patrimonio artístico español. Esta información contribuirá al hallazgo de productos y tratamientos más adecuados para la conservación y restauración de esta técnica, todavía en ocasiones no suficientemente reconocida y, por lo general, en mal estado de conservación, que, por sus características materiales, implica serias dificultades para su correcta intervención.

El análisis comparativo de motivos de brocados de estaño en relieve aplicados con documentación bibliográfica permite la datación y, en algunos casos, la atribución de obras de arte. En último lugar, esto puede ampliar nuestro conocimiento sobre los talleres y artesanos que emplearon la técnica del brocado de estaño en relieve aplicado.

El glosario de términos proporcionado ayuda a la correcta interpretación de las fuentes escritas sobre el tema y, con ello, se propone como herramienta de ayuda que facilite el intercambio de conocimientos en futuras investigaciones. Asimismo, una posible futura línea de estudio detectada es la visión historiográfica de la terminología empleada en cada variante decorativa. Un análisis crítico de la bibliografía resultaría de gran interés para conocer la evolución y transformación de los términos en distintos idiomas y establecer comparativas que ayudaran a comprender el todavía extenso y no unificado vocabulario técnico con el que aún se designan las técnicas pictóricas en relieve por adición.

100 J. de Miguel, C. Gómez, J.A. Salazar, Brocado aplicado. Nuevas aportaciones, pp. 284, 285; M. Luciañez, Catalogación y estudio del Brocado Aplicado, pp. 43, 52, 63. 


\section{GLOSARIO DE TÉRMINOS SOBRE TÉCNICAS PICTÓRICAS EN RELIEVE POR ADICIÓN}

El vocabulario técnico utilizado en las fuentes documentales hasta el presente para referirse al amplio abanico de técnicas de pintura en relieve, incluidas las obtenidas por adición, que podemos observar en una gran diversidad de obras de arte fuera y dentro de las fronteras españolas, nunca ha sido objeto de estudio. Así nos encontramos que a veces un término incorrecto (estilística, técnica, materialmente...) se emplea para referirse a una técnica, otras veces se designan técnicas diferentes con el mismo vocablo y otras veces se utilizan varios vocablos para señalar una misma técnica. El panorama actual es, en consecuencia, confuso ${ }^{101}$.

Con el propósito de poner a disposición de los especialistas una terminología específica y unificada que ayude a la difusión de conocimientos en esta materia, a continuación se aporta un glosario preciso y actualizado de las siete técnicas pictóricas en relieve por adición, previamente mencionadas, que definen la evolución del brocado de estaño en relieve aplicado. Se muestran en orden cronológico, de mayor a menor antigüedad, incluyendo, en cada caso, los diferentes términos con que se designan en las fuentes bibliográficas de distintos países e idiomas acompañados de una descripción del proceso de construcción.

\subsection{Metal recortado}

Otra terminología para referirse a la técnica ${ }^{102}$ : flat metal foil ornament, flat metal application, applied sheet metal, sheet-metal ornament, metal application.

Descripción de la técnica: Uno de los metales más utilizados es la lámina de estaño. Ésta se cubre con lámina de oro puro o, más frecuentemente, con corladura amarilla para imitar el color del oro. Después se recorta en las formas deseadas. Finalmente se aplica sobre la superficie de la obra previamente cubierta con cera, barniz ${ }^{103}$ o una masa de agua de goma y pigmento blanco que, una vez seca, se pule con piedra de ónix y se vuelve a cubrir con agua de goma $^{104}$.

101 J. Nadolny, The gilded tin-relief backgrounds, p. 183.

102 Ibidem, p. 174; E. Woolley, J. Nadolny, L. Shekede, Tin relief on thirteenth-century Cypriot wall painting, pp. 331, 333, 334, 338

103 C. Cennini, El Libro del Arte, pp. 140-144, 179.

104 M.J. González, Brocado aplicado, p. 69. 


\subsection{Papel recortado}

Otra terminología para referirse a la técnica: paper relief.

Descripción de la técnica: Se parte de láminas de papel que, una vez doradas, son recortadas a mano alzada o con troquel creando formas distin$\operatorname{tas}^{105}$. Posteriormente se adhieren con una capa extra de adhesivo sobre la superficie de la obra.

\subsection{Relieve a mano alzada}

Otra terminología para referirse a la técnica ${ }^{106}$ : free-hand relief decoration, appliqué relief, Plasterrelief, pastillage, relieve en yeso, barbotina, brocado de tres altos, relieve en estuco, yesería, pastiglia, pastiglio, opera di mazzonaria, pastillaje.

Descripción de la técnica: Un material en estado líquido o semilíquido se aplica sobre la preparación de la obra a mano alzada de diferentes formas; con pincel (superponiendo capas hasta lograr la altura deseada), con una manga a presión provista de una abertura especialmente dispuesta, o con la mano modelando primero los motivos a mano alzada y aplicándolos a continuación. La sustancia que se usa para crear el relieve suele ser igual en composición a la de la preparación de la obra (yeso o creta y cola animal) lo que permite una mayor compatibilidad material entre ambas y una mejor conservación. Esta sustancia es además autoadhesiva, es decir, el material aglutinante no sólo funciona como tal si no también como adhesivo, uniendo el relieve a la preparación ${ }^{107}$. Esto explica que se aplique antes de que seque. En comparación, todas las demás variantes de relieve obtenidas por adición requieren de una capa extra de adhesivo para adherirse a la obra ${ }^{108}$. Una vez seco, a veces se dora con lámina de oro al mixtión acabado en mate ${ }^{109}$.

105 J. Nadolny, The techniques and use of gilded relief decoration, vol. I, p. 43.

106 O. Cantos, Restauración del retablo mayor, p. 216; M. Hamsík, The relief decoration of medieval painting-pastiglia, p. 100; M. Serck-Dewaide, Relief decoration on sculptures and paintings, p. 36 .

107 J. Nadolny, The techniques and use of gilded relief decoration, vol. I, p. 43; M. SerckDewaide, Décors en relief, p. 91.

108 J. Nadolny, The gilded tin-relief backgrounds, p. 183.

109 M. Serck-Dewaide, The history and conservation, p. 67. 


\subsection{Relieve moldeado simple}

Otra terminología para referirse a la técnica ${ }^{110}$ : simple cast relief, Modeln gepresstes Stuckornament, Pressmasse, Reliefsmuck, Stuck-masse.

Descripción de la técnica: Se rellena un molde o matriz con una sustancia líquida o semilíquida. Dado que no se utiliza lámina de estaño entre el molde y la masa de relleno, para proporcionar mayor resistencia a la masa y facilitar su extracción del molde y su posterior manipulación, los motivos resultantes tienden a ser gruesos para que no se deterioren durante su manejo ${ }^{111}$. Esto supone un tipo de masa muy específica, por regla general, elaborada con creta, cola (seguramente animal) y agua en proporciones muy concretas, lo que también permite un moldeado definido. Cuando la pasta introducida en la matriz está seca se desprende con ligeros toques para no forzar la separación y evitar deterioros en el relieve. Antes de su aplicación en la obra (sobre la preparación, la superficie dorada o la capa pictórica), el motivo se humedece para que recupere su flexibilidad y se fija con una capa de adhesivo. Por último, se suele dorar con lámina de oro al mixtión acabado en mate ${ }^{112}$.

\subsection{Papel moldeado}

Otra terminología para referirse a la técnica: cast paper.

Descripción de la técnica: Se realiza una pasta con fibras o pequeños fragmentos de papel y una cierta cantidad de cola animal para lograr una sustancia adecuada que permita un modelado satisfactorio. Esta pasta se coloca en una matriz ${ }^{113}$ y se comprime con presión a través de, por ejemplo, una prensa ${ }^{114}$. Una vez que la masa de papel ha endurecido, se retira de la matriz y con un adhesivo se aplica sobre la zona de la obra que se desea adornar. A continuación se cubre con lámina de oro aplicada con mixtión ${ }^{115}$ y acabado en mate.

110 Idem, Relief decoration on sculptures and paintings, pp. 36, 37.

111 J. Nadolny, The techniques and use of gilded relief decoration, vol. I, p. 44.

112 M. Serck-Dewaide, Décors en relief: Approche technologique et historique, p. 91.

113 Según las fuentes documentales más antiguas que citan esta técnica, los moldes para crear motivos a base de papel eran de cobre o de plomo. Véase J. Nadolny, Documentary Sources, p. 44.

114 Idem, The techniques and use of gilded relief decoration, vol. I, p. 40.

115 T. Gómez, Policromía del gótico final, p. 577. 


\subsection{Relieve de estaño}

Otra terminología para referirse a la técnica: tin-relief, Pressbrokat.

Descripción de la técnica: Sobre una matriz o molde ${ }^{116}$ se dispone una o más láminas de estaño que son presionadas contra el molde. Los huecos resultantes se rellenan con una sustancia líquida o semilíquida compuesta de distintas mezclas de materiales ${ }^{117}$. Una vez seca la masa de relleno se separa la lámina de estaño de la matriz. Las piezas son recortadas de la lámina de estaño y adheridas a la obra (sobre la preparación, la superficie dorada o la capa pictórica) con una capa de adhesivo ${ }^{118}$ y a continuación se doran al mixtión ${ }^{119}$. En casos puntuales se ha detectado estaño visto sin ningún tipo de recubrimiento, así como corladura amarilla que, utilizada sobre la lámina de estaño, ofrece la apariencia de oro ${ }^{120}$. También, para destacar el volumen de los relieves, se ha identificado pintura sobre los fondos planos del estaño previamente cubierto con corladura amarilla ${ }^{121}$.

\subsection{Brocado de estaño en relieve aplicado}

Otra terminología para referirse a la técnica ${ }^{122}$ : applied brocade, brocade application, pressed brocade, press brocade, relief brocade, tin-relief textile, applied tin-relief brocade, brocart appliqué, brocade appliqué, appliqué relief, appliqué relief brocade, appliqué relief brokad, wax appliqué, Pre $\beta$ brokat, Pressbrokat, Pressbrokat-applikationen, Pressbrokat-applikation, Brokatapplikationen, brocado aplicado, brocado de aplicación, press brocaat.

116 A diferencia del brocado de estaño en relieve aplicado, existen moldes originales de motivos de relieves de estaño (véase J.A. Darrah, White and Golden Tin Foil, p. 57). También la bibliografía antigua apunta diferentes materiales para los moldes, como la piedra, el cobre, el latón y el plomo (véase C. Cennini, El Libro del Arte, pp. 165, 210; J. Nadolny, Documentary Sources, pp. 42-44).

117 J.A. Darrah, White and Golden Tin Foil, p. 55; E. Woolley, J. Nadolny, L. Shekede, Tin relief on thirteenth-century Cypriot wall painting, p. 334.

118 Motivos de relieve de estaño recientemente localizados en uno de los pocos ejemplos de pintura mural del siglo XIII en Chipre, confirman el empleo de un adhesivo orgánico proteínico y lipídico. Véase ibidem, p. 334.

119 J. Nadolny, Documentary Sources, pp. 40, 42, 47.

120 Idem, The techniques and use of gilded relief decoration, vol. I, p. 45.

121 E. Woolley, J. Nadolny, L. Shekede, Tin relief on thirteenth-century Cypriot wall painting, p. 334 .

122 J.A. Darrah, White and Golden Tin Foil, pp. 49, 50; P.L. Echeverría, Contribución del País Vasco a las artes pictóricas del Renacimiento, p. 86; M.J. González, Brocado aplicado, p. 68; L.F. Jacobs, Early Netherlandish carved altarpieces, 1380-1550, p. 82; J. Nadolny, The gilded tin-relief backgrounds, p. 183. 
Descripción de la técnica (véase introducción): El proceso de ejecución es muy similar al del relieve de estaño. Se parte de una matriz grabada con un motivo de brocado. La matriz se cubre con lámina de estaño y se rellenan los huecos con una masa de relleno. Cuando la masa está seca, se desprende la lámina de estaño de la matriz y el motivo resultante se recorta y aplica encima de la obra, pudiendo estar en ocasiones dorado y pintado ${ }^{123}$.

\section{BIBLIOGRAFÍA CITADA}

Arrazola Echeverría, María Asunción; Martiarena Lasa, Xavier; Barriola Olano, Maite; Berasain Salvarredi, Ion; Larrañaga, Ion; Okaranza, Ricardo, Bidaurretako erretaula errenazentista: zaharberritzea/Retablo renacentista de Bidaurreta: restauración, San Sebastián, Patrimonio Histórico Artístico, Departamento de Cultura, Diputación Foral de Gipuzkoa, 1991.

Bachmann, Karl Werner; Oellermann, Eike; Taubert, Johannes, The conservation and technique of the Herlin altarpiece (1466), "Studies in Conservation" 15/4 (1970), pp. 327-369.

Ballestrem, Agnes, Un témoin de la conception polychrome des retables bruxellois au début du XVIe siècle, "Bulletin de l'Institut Royal du Patrimoine Artistique" 10 (1967/1968), pp. 36-45.

Barrio Loza, José Ángel; Equipo 7 Restauración SA, El retablo mayor del Santuario de la Encina de Arceniega en Álava, Bilbao, Iberdrola SA, 1999.

Bartl, Anna; Krekel, Christoph; Lautenschlager, Manfred; Oltrogge, Doris, Der "Liber illuministarum" aus Kloster Tegernsee. Edition, Übersetzung und Kommentar der kunsttechnologischen Rezepte, Stuttgart, Franz Steiner Verlag - Germanisches National Museum, 2005.

Bartolomé García, Fernando R.; Servicio de Restauración DFA; CROMA, Calvario del Santo Cristo. Santuario de Nuestra Señora de la Encina. Artziniega (Álava). Historia y restauración, Vitoria-Gasteiz, Diputación Foral de Álava, 2009.

Berasain Salvarredi, Ion; Barriola Olano, Maite, Aproximación a la policromía del retablo de San Antón. Parroquia de San Pedro de Zumaia (Gipuzkoa), "Ondare. Cuadernos de Artes Plásticas y Monumentales: Revisión del Arte del Renacimiento" 17 (1998), pp. 377-387.

Bermejo Martínez, Elisa, La pintura de los primitivos flamencos en España, vol. I, Madrid, Consejo Superior de Investigaciones Científicas - Instituto Diego Velázquez, 1980.

123 Idem, A survey of the technical research into the techniques of tin-relief and pressbrokat. 
Bowman, Cynthia L., Pasteprints: a new hypothesis about their production, "Print Quarterly" 2/1 (1985), pp. 4-11.

Brachert, Thomas, Pressbrokat-Applikationen, ein Hilfsmittel für die Stilkritik, dargestellt an einer Werkstatt der Spätgotik, "Jahresbericht" (1963), pp. 37-47.

Broekman-Bokstijn, Marjolein; Van Asperen de Boer, J.R.J.; Van'T Hul-Ehrnreich, Emilie Helena; Verduyn-Groen, C.M., The Scientific examination of the polychromed sculpture in the Herlin altarpiece, "Studies in Conservation" 15/4 (1970), pp. 370-400.

Bruquetas, Rocío; Carrassón, Ana; Gómez Espinosa, Teresa, Los retablos. Conocer y conservar, "Bienes Culturales. Revista del Instituto del Patrimonio Histórico Español. Retablos" 2 (2003), pp. 12-47.

Cantos Martínez, Olga, Restauración del retablo mayor de la iglesia de San Miguel de los Navarros (Zaragoza). Recuperación de los brocados aplicados, "Sautuola. Revista del Instituto de Prehistoria y Arqueología Sautuola" 9 (2002-2003), pp. 483-508.

Cennini, Cennino, El Libro del Arte, Madrid, Ediciones Akal, 1988.

Darrah, Josephine A., White and golden tin foil in applied relief decoration: 1240-1530, en Hermens, E. (ed.), Looking through paintings. The study of painting techniques and materials in support of art historical research, Leiden, De Prom and Archetype Publications, 1998, pp. 49-79.

Echeverría Goñi, Pedro Luis, Contribución del País Vasco a las artes pictóricas del Renacimiento: la pinceladura norteña, "Ondare. Cuadernos de Artes Plásticas y Monumentales: Revisión del Arte del Renacimiento" 17 (1998), pp. 73-106.

Echeverría Goñi, Pedro Luis, El retablo en el País Vasco. Estado de la cuestión, en Echeverría Goñi, P.L. (dir. y coord.), Retablos. Euskadi. Catálogos del Centro de Patrimonio Cultural Vasco, Vitoria-Gasteiz, Servicio Central de Publicaciones del Gobierno Vasco, 2001, vol. I, pp. 76-81.

Equipo 7 Restauración SA, Proceso de restauración del retablo mayor del Santuario de la Encina, en Barrio Loza, J. A.; Equipo 7 Restauración, El retablo mayor del Santuario de la Encina de Arceniega en Álava, Bilbao, Iberdrola SA, 1999, pp. 45-76.

Estrade Alda, María Milagros, El Brocado aplicado, una técnica insólita empleada en el retablo de Santa María de Galdakao (Bizkaia), en VII Congreso de Conservación de Bienes Culturales: Bilbao 23, 24 y 25 de Septiembre de 1988, Vitoria-Gasteiz, Servicio Central de Publicaciones del Gobierno Vasco, 1991, pp. 126-136.

Frinta, Mojmír S., The use of wax for appliqué relief brocade on wooden statuary, "Studies in Conservation" 8/4 (1963), pp. 136-147. 
García Ramos, Rosaura; Ruiz de Arcaute Martínez, Emilio, Aproximación al brocado aplicado en España: desarrollo y extensión, en XI Congreso de Conservación y Restauración de Bienes Culturales: Castellón, 3, 4, 5 y 6 de Octubre de 1996, Castellón, Servei de Publicacions Diputació de Castelló, 1996, pp. 747-756.

García Ramos, Rosaura; Ruiz de Arcaute Martínez, Emilio, El "brocado aplicado", una técnica de policromía centroeuropea en Álava, "Ondare. Cuadernos de Artes Plásticas y Monumentales: Revisión del Arte del Renacimiento" 17 (1998), pp. 409-421.

García Ramos, Rosaura; Ruiz de Arcaute Martínez, Emilio, The conservation and restoration of the polychrome sculpture in Álava. The main altarpiece of San Vicente de Arana and the bust-reliquaries of the church of San Miguel de Vitoria, en Polychrome Skulptur in Europa. Technologie, Konservierung, Restaurierung. Tagungsbeiträge. 11-13 November 1999, Dresde, Hochschule für Bildende Kunste, 1999, pp. 84-89.

Geelen, Ingrid; Steyaert, Delphine, Imitation and Illusion. Applied Brocade in the Art of the Low Countries in the Fifteenth and Sixteenth Centuries, Bruselas, KIK/IRPA, 2011.

Gómez Espinosa, Teresa, El retablo mayor de la catedral de Toledo. Estilo y policromía, en Las Catedrales en España. Actas Jornadas Técnicas de Conservadores de Catedrales. Alcalá de Henares, 5 y 6 de noviembre de 1998, Alcalá de Henares, Servicio de Publicaciones de la Universidad de Alcalá de Henares, 1998, vol. II, s.p.

Gómez Espinosa, Teresa, Policromía del gótico final. Retablo mayor de la catedral de Toledo y obras burgalesas de Gil Siloe, en Yarza, J.; Ibáñez, A.C. (dir.), Gil Siloe y la Escultura de su época, Actas del Congreso Internacional, Burgos 13-16 octubre de 1999, Burgos, Institución Fernán González - Academia Burgense de Historia y Bellas Artes Caja de Burgos, 2001, pp. 573-582.

Gómez Moreno, María Elena, La policromía en la escultura española, Madrid, Escuela de Artes y Oficios Artísticos de Madrid, 1943.

González López, María José, Brocado aplicado: fuentes escritas, materiales y técnicas de ejecución, "PH Boletín del Instituto Andaluz del Patrimonio Histórico" 8/31 (2000), pp. 67-77.

Hamsík, Mojmír, The relief decoration of medieval painting-pastiglia: origin and technique, "Umení: casopis Kabinetu theorie a dejin umení Ceskoslovenske akademie" 40/2 (1992), pp. 100-107.

Hecht, Brigitte, Betrachtungen über pressbrokate sowie Rekonstruktionsversuche unter besonderer Berücksichtigung des sog. Tegernseer Manuskripts, Stuttgart, Institut für Technologie der Malerei, 1980 (trabajo de investigación inédito). 
Jacobs, Lynn F., Early Netherlandish carved altarpieces, 1380-1550. Medieval tastes and mass marketing, Nueva York, Cambrige University Press, 1998.

Koller, Manfred, Zur technologie der pastiglia vom 13. bis 20. jahrhundert, en Mirabilia et curiosa, Viena, Mayer \& Comp., 2000, pp. 121-125.

Luciañez Triviño, Miriam, Catalogación y estudio del Brocado Aplicado en los Retablos del Territorio Histórico Alavés, Valencia, Universidad Politécnica de Valencia, 2009 (tesina de Master inédita).

Miguel Ortego, Javier de; Gómez Cambronero, Cristina; Salazar López, José Antonio, Brocado aplicado. Nuevas aportaciones, en $X$ Congreso de Conservación y Restauración de Bienes Culturales: Cuenca, 29, 30 de Septiembre, 1, 2 de octubre de 1994, Cuenca, Ministerio de Cultura de España - Congreso de Conservación y Restauración de Bienes Culturales, 1994, pp. 281-291.

Muñiz Petralanda, Jesús, El retablo gótico esculpido, en Echeverría Goñi, P. L. (dir. y coord.), Retablos. Euskadi. Catálogos del Centro de Patrimonio Cultural Vasco, Vitoria-Gasteiz, Servicio Central de Publicaciones del Gobierno Vasco, 2001, vol. I, pp. 116-145.

Muñiz Petralanda, Jesús, Reflejos de Flandes. La escultura mueble Tardogótica en Bizkaia, Bilbao, Museo Diocesano de Arte Sacro, 2011.

Nadolny, Jilleen, A survey of the technical research into the techniques of tinrelief and pressbrokat, "Technologia Artis" 4 (1996), pp. 42-47.

Nadolny, Jilleen, The techniques and use of gilded relief decoration by northern European painters, c. 1200-1500, Londres, Courtauld Institute of Art, 2000 (tesis doctoral inédita).

Nadolny, Jilleen, The gilded tin-relief backgrounds of the Thornham Parva retable and the Cluny Frontal: technical and stylistic context, en Massing, A. (ed.), The Thornham Parva Retable. Technique, conservation and context of an English medieval painting, Cambridge, The Hamilton Kerr Institute University of Cambridge - Harvey Miller Publishers, 2003, pp. 174-188.

Nadolny, Jilleen, One craft, many names: gilders, preparers, and polychrome painters in the 15th and 16th centuries, en Diversity in heritage conservation: tradition, innovation and participation, ICOM-CC 15th Triennial Conference New Delhi 22-26 September 2008, Nueva Delhi, Allied Publishers, 2008, vol. I, pp. 10-17.

Nadolny, Jilleen, Documentary Sources for the use of Moulds in the Production of Tin Relief: Cause and Effect, en Hermens, E.; Townsend, J. (eds.), Sources and Serendipity: Testimonies of Artists' Practice. ICOM-CC Working Group on Art Technological Source Research (ATSR) 3rd International Symposium, Scotland, 12-13 June 2008, Londres, Archetype Press Ltd., 2009, pp. 39-49.

ANUARIO DE Estudios MEdiEvales, 44/2, julio-diciembre 2014, pp. 945-981 ISSN 0066-5061, doi:10.3989/aem.2014.44.2.09 
Rodríguez López, Ainhoa, Decoración policroma en relieve. El brocado aplicado. Materiales, técnicas y conservación, "Restauración \& Rehabilitación (R \& R). Revista Internacional del Patrimonio Histórico" 105 (2007), pp. 66-71.

Rodríguez López, Ainhoa, Análisis y clasificación de los brocados aplicados de los retablos de Guipúzcoa, Lejona, Servicio Editorial de la Universidad del País Vasco, 2010.

Rodríguez López, Ainhoa; Bazeta Gobantes, Fernando, Classification of the Typologies, Techniques and Materials of the Applied Brocades of the Altarpieces of Gipuzkoa by Means of the Analytical Techniques of Laboratory, en 9th Internacional Conference on ART2008. Non-destructive investigations and microanalysis for the diagnostics and conservation of cultural and environmental heritage, Jerusalén, ISAS International Seminars, 2008, pp. 1-10.

Rodríguez López, Ainhoa; Bazeta Gobantes, Fernando, El brocado aplicado en la retablería renacentista de Guipúzcoa. Un estudio para su clasificación, "Ondare. Cuadernos de Artes Plásticas y Monumentales" 27 (2009), pp. 297-331.

Rodríguez López, Ainhoa; Bazeta Gobantes, Fernando; Escohotado Ibor, María Teresa, El "brocado de estaño en relieve aplicado" en el Condado de Treviño. Estudio comparativo con los casos analizados en Guipúzcoa, en González de Viñaspre Gonzalo, R.; Garay Osma, R. (ed.), Viaje a Íbita. Estudios históricos del Condado de Treviño. I Congreso de Estudios Históricos del Condado de Treviño. 1, 2 y 3 de junio de 2011, Condado de Treviño, Ayuntamiento de Condado de Treviño, 2012, pp. 293-310.

Rodríguez López, Ainhoa; Khandekar, Narayan; Bazeta Gobantes, Fernando; Escohotado Ibor, María Teresa, Materials and Execution Process of the Relief Painting Technique of "Applied Brocade" in the Basque Country (Spain), en Polychrome Sculpture: Decorative practice and artistic tradition. SPAD Interim Meeting (ICOM-CC), Tomar-Portugal, 28-29 May 2013. (De próxima publicación).

Rodríguez López, Ainhoa; Eremin, Katherine; Khandekar, Narayan; Stenger, Jens; Newman, Richard; Bazeta Gobantes, Fernando; Escohotado Ibor, María Teresa, Characterization of calcium sulfate grounds and fillings of applied tin-relief brocades by Raman spectroscopy, Fourier transform infrared spectroscopy and scanning electron microscopy, "Journal of Raman Spectroscopy. Special issue: Raman Spectroscopy in Art and Archaeology" 41/11 (2010), pp. 1227-1234. Serck-Dewaide, Myriam, Décors en relief: Approche technologique et historique, en Le Retable d'Issenheim et la sculpture au Nord des Alpes 
à la fin du Moyen Âge. Actes du Colloque de Colmar (2-3 Novembre 1987), Colmar, Musée d'Unterlinden, 1989, pp. 90-97.

Serck-Dewaide, Myriam, Relief decoration on sculptures and paintings from the thirteenth to the sixteenth century: technology and treatment, en Mills, J. S.; Smith, P. (ed.), Cleaning, retouching and coatings: Technology and practice for easel paintings and polychrome sculpture, Preprints of the contributions to the thirteenth IIC Brussels Congress, 3-7 September 1990, Londres, International Institute for Conservation, 1990, pp. 36-40.

Serck-Dewaide, Myriam, The history and conservation of the surface coating on European gilded-wood objects, en Bigelow, D.; Cornu, E.; Landrey, G.J.; Van Horne, C. (eds.), Gilded Wood. Conservation and history. Gilding Conservation Symposium, October 1988, MadisonConnecticut, Sound View Press, 1991, pp. 65-78.

Serck-Dewaide, Myriam, Support and polychromy of altarpieces from Brussels, Mechlin, and Antwerp: study, comparison, and restoration, en Dorge,V.; Howlett, F. C. (eds.), Painted Wood: History and Conservation. Proceedings of a symposium organized by the Wooden Artifacts Group of AIC. Williamsburg, Virginia, 11-14 November 1994, Los Ángeles, The Getty Conservation Institute, 1998, pp. 82-99.

Tavares Da Silva, Alice, The decorated background, en Massing, A. (ed.), The Thornham Parva Retable. Technique, conservation and context of an English medieval painting, Cambridge, The Hamilton Kerr Institute University of Cambridge - Harvey Miller Publishers, 2003, pp. 47-53.

Westhoff, Hans; Hahn, Roland; Kollmann, Annette; Klöpfer, Anette, Graviert, gemalt, gepresst: spätgotische retabelverzierungen in Schwaben, Stuttgart, Württembergisches Landesmuseum Stuttgart, 1996.

Wethey, Harold Edwin, Gil de Siloe and his school: a study of late gothic sculpture in Burgos, Cambridge, Harvard University Press, 1936.

Woolley, Elizabeth; Nadolny, Jilleen; Shekede, Lisa, Tin relief on thirteenthcentury Cypriot wall painting: Technology and conservation, en The Decorative: Conservation and the Applied Arts. Preprints of the 24th IIC Congress, 10-14 September, 2012, Vienna, Londres, IIC, 2012, pp. 331-339.

Fecha de recepción del artículo: septiembre 2012

Fecha de aceptación y versión final: julio 2013 